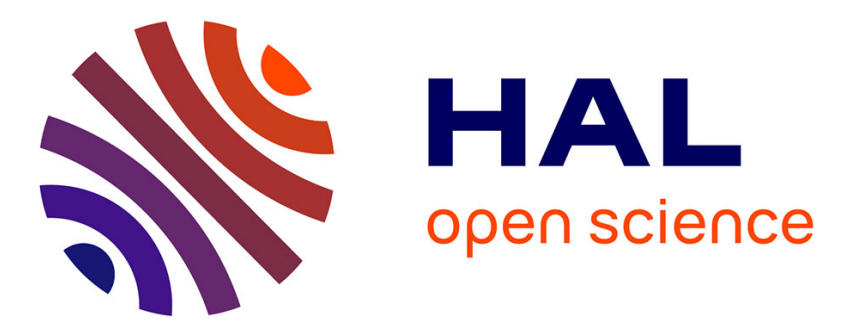

\title{
Heat flow and thickness of the lithosphere in the Canadian Shield
}

Claude Jaupart, Jean-Claude Mareschal, Laurent Guillou-Frottier, Anne

Davaille

\section{- To cite this version:}

Claude Jaupart, Jean-Claude Mareschal, Laurent Guillou-Frottier, Anne Davaille. Heat flow and thickness of the lithosphere in the Canadian Shield. Journal of Geophysical Research : Solid Earth, 1998, 103, pp.15269-15286. 10.1029/98JB01395 . hal-00562366

\section{HAL Id: hal-00562366 https://hal-brgm.archives-ouvertes.fr/hal-00562366}

Submitted on 30 Jul 2020

HAL is a multi-disciplinary open access archive for the deposit and dissemination of scientific research documents, whether they are published or not. The documents may come from teaching and research institutions in France or abroad, or from public or private research centers.
L'archive ouverte pluridisciplinaire HAL, est destinée au dépôt et à la diffusion de documents scientifiques de niveau recherche, publiés ou non, émanant des établissements d'enseignement et de recherche français ou étrangers, des laboratoires publics ou privés. 


\title{
Heat flow and thickness of the lithosphere in the Canadian Shield
}

\author{
C. Jaupart \\ Institut de Physique du Globe de Paris \\ J.C. Mareschal and L. Guillou-Frottier ${ }^{1}$ \\ GEOTOP, Centre de Recherche en Géochimie isotopique et Géochronologie \\ Université du Québec à Montréal, Québec, Canada
}

\author{
A. Davaille \\ Institut de Physique du Globe de Paris
}

\begin{abstract}
Heat flow and radioactive heat production data were obtained in the Canadian Shield in order to estimate the crustal heat production and the mantle heat flow. Several methods have been used to determine radioactive heat production in the crust. The analysis yields values for the mantle heat flow in the craton that are consistently between 7 and $15 \mathrm{~mW} \mathrm{~m}^{-2}$. Assuming that the lithosphere is in thermal equilibrium, we investigate the conditions for small-scale convection to supply the required heat flux through its base. For a given creep law, the thickness of the lithosphere, the temperature at the base of the lithosphere, and the effective viscosity of the mantle are determined from the value of the mantle heat flow beneath the shield. The viscosity of the mantle depends on the creep mechanism and on the fluid content. Wet diffusion creep implies a viscosity between $10^{20}$ and $10^{21} \mathrm{~Pa} \mathrm{~s}$, corresponding to a mantle temperature of $1620 \mathrm{~K}$ at a depth of $250 \mathrm{~km}$. The other creep mechanisms can be ruled out because they imply values for viscosity and temperature inconsistent with geophysical data. For a given creep law, there is a minimum mantle temperature below which equilibrium cannot be reached. For wet diffusion creep, this minimum mantle temperature $(1780 \mathrm{~K}$ at $280 \mathrm{~km}$ depth) is close to that of the well-mixed (isentropic) oceanic mantle at the same depth. For a thermally stable lithosphere, our model requires the mantle heat flow to be at least $13 \mathrm{~mW} \mathrm{~m} \mathrm{~m}^{-2}$ and the compositional lithosphere to be less than $240 \mathrm{~km}$.
\end{abstract}

\section{Introduction}

Heat flow data have been used to investigate the thermal structure and composition of the lithosphere. Early studies have used the measured surface heat flow as a constraint on the composition of the Earth [Birch, 1954; Wasserburg et al., 1964; Clark and Ringwood, 1964]. The pattern of oceanic heat flow is well explained by the cooling plate model [Sclater and Francheteau, 1970; Parker and Oldenburg, 1973]. For the continents the heat flow includes a large contribution of crustal radioactivity. The average heat flow does not vary significantly for provinces older than $400 \mathrm{Ma}$ [Sclater et

\footnotetext{
${ }^{1}$ Now at Bureau de Recherches Géologiques et Minières, Orléans, France.
}

Copyright 1998 by the American Geophysical Union.

Paper number 98JB01395.

0148-0227/98/98JB-01395\$09.00 al., 1980] and, only in Archean provinces, it might be lower than in younger terranes [Morgan, 1985]. The reason for the lower heat flow of Archean provinces is still debated. Some authors suggest lower crustal heat production [e.g., Morgan, 1985; Pinet et al., 1991; Lenardic, 1997]. According to others [e.g., Nyblade and Pollack, 1993], cratons are thicker than the surrounding provinces, which acts to divert heat away from them. Jordan $[1975,1978]$ proposed differences in upper mantle composition between the continents and the oceans. According to him, basaltic melts were extracted from the upper mantle beneath the continents when the cratons stabilized. There is thus a chemical boundary layer beneath shield areas, which does not take part in the mantle convection.

The discrimination between crustal heat production and the mantle component of heat flow is essential to characterize the thermal structure of the lithosphere. Recent determinations of the average crustal heat production vary within a large range of 0.7 to $1.3 \mu \mathrm{W} \mathrm{m} \mathrm{m}^{-3}$ [Wedepohl, 1991; Rudnick and Founiain, 1995; Taylor 
and McLennan, 1995]. Such bulk estimates rely on assumptions regarding the average structure and thickness of the continental crust and may not easily be compared to surface heat flow values which represent a different statistical sample. Comparing the local heat flow distribution and crustal structure in a well-known geological province should give more reliable estimates, but this procedure is seldom used. Many authors have assumed that the mantle heat flow is $\approx 25 \mathrm{~mW} \mathrm{~m} \mathrm{~m}^{-2}$ in stable continental regions, because this is the lowest measured value [e.g., Pollack and Chapman, 1977; Cermak and Bodri, 1986]. This requires the whole crust below specific measurement sites to be completely devoid of heat-producing elements. On the other hand, the analysis of heat flow and heat production data in the Norwegian Shield led Smithson and Ramberg [1979] and Pinet and Jaupart [1987] to conclude that the mantle heat flow is about $11 \mathrm{~mW} \mathrm{~m} \mathrm{~m}^{-2}$. Such a value is much lower than what has been commonly assumed in studies of the continental lithosphere.

In order to determine the relative contributions of mantle heat flow and crustal radioactivity to the total heat flow at the surface, a program of heat flow measurements was undertaken in the Canadian Shield [Mareschal et al., 1989; Pinet et al., 1991; Guillou et al., 1994; Guillou-Frottier et al., 1995, 1996]. The Canadian Shield has not been active tectonically for $1000 \mathrm{Ma}$ and it juxtaposes Provinces of different ages. It exposes different crustal levels, and there is an extensive data set on the $\mathrm{U}, \mathrm{Th}$, and $\mathrm{K}$ concentrations of the major rock types allowing reconstruction of crustal columns [ $A s h$ wal et al., 1987; Fountain et al., 1987]. This makes the Canadian Shield a very favorable region to undertake a study of crustal heat production. In this paper, we shall first outline how the Canadian Shield data constrain crustal heat production and mantle heat flow. We shall explain how we calculated the mantle heat flow and obtained by various methods values that are consistently lower than $15 \mathrm{~mW} \mathrm{~m}^{-2}$. For such low values of the mantle heat flow, temperature profiles at depth do not intersect the mantle solidus [Pollack and Sass, 1988; McKenzie, 1989]. Thus one must specify other conditions at the base of the lithosphere. Chapman [1986] required that the base of the lithosphere lies along a mantle adiabat. However, this assumes that the mantle is well mixed everywhere, which is supported neither by tomographic images [Montagner, 1994] nor by dynamical models of mantle convection with continents [Gurnis, 1988; Guillou and Jaupart, 1995; Lenardic and Kaula, 1996; Doin et al., 1997]. Furthermore, this approach neglects the coupling between the lithosphere and the convecting mantle. From the thermal point of view, the lithosphere may be defined as a thermal boundary layer where heat is transported by conduction. This heat must be provided by the underlying mantle, implying the existence of a convective boundary layer beneath the lithosphere. Because temperature varies continuously through these different layers, tomo- graphic images lump them together. In the second part of this paper, we will examine the implications of the mantle heat flow value for the transport of heat into the lithosphere. We shall discuss how lithospheric thickness and mantle heat flow can be calculated from a model of heat transport into the lithosphere.

\section{Mantle Heat Flow Beneath the Canadian Shield}

\subsection{Heat Flow and Heat Production in the Canadian Shield}

Early attempts to calculate mantle heat flow relied on an empirical relationship between heat flow and heat production rate, the so-called linear heat flow relation [Birch et al., 1968; Roy et al., 1968; Lachenbruch, 1970]. It was suggested that crustal heat production decreases exponentially as a function of depth down to the Moho. Independent verification from direct determinations of crustal composition was not possible as little was known about the lower crust. Indeed, the linear heat flow relation was used by geochemists to constrain the composition of the lower crust [Taylor and McLennan, 1985].

During the past 25 years, there has been much progress in our understanding of continental heat flow. First, the significance of the empirical heat flow relationship has been questioned [England et al., 1980; Jaupart, 1983]. With more data available, the number of anomalies from the relation has increased [e.g., Jaupart et al., 1981]. Also, it was shown that for the rather small wavelengths involved, surface heat flow is only sensitive to shallow heat production contrasts [Jaupart, 1983; Vasseur and Singh, 1986]. Second, a better evaluation of the lower crustal component has resulted from systematic investigations of large granulite facies terrains [Fountain and Salisbury, 1981; Ashwal et al., 1987; Fountain et al., 1987] and xenoliths suites [Rudnick, 1992]. It was shown that granulite facies terrains which are found today at the Earth's surface had resided for extended periods of time at depth and hence are truly representative of the lower crust [Mezger, 1992]. The heat production values of granulite facies terranes in different areas of the Superior Province are very consistent $\left(\approx 0.4 \mu \mathrm{W} \mathrm{m}^{-3}\right)$, and appear to be representative of all granulite facies terranes worldwide [Pinet and Jaupart, 1987]. Third, the number of heat flow determinations in Archean and Precambrian provinces has increased. In the Canadian Shield the number of heat flow measurements has been multiplied by more than four since the compilation of Jessop et al. [1984] [Drury, 1985; Drury and Taylor, 1987; Mareschal et al., 1989; Pinet et al., 1991; Guillou et al., 1994; GuillouFrottier et al., 1995, 1996]. It was shown that for the Archean Abitibi subprovince where surface rocks have low heat production, there is no relationship between surface heat flow and surface heat production. Finally, the structure of the deep crust is better known from both gravity and seismic studies [e.g., Clowes et al., 
1992]. It was confirmed that the lower crust is as heterogeneous as exposed granulite facies terrains. It was also found that crustal thickness is variable [e.g., Green et al., 1988; Percival et al., 1989] and could be substantially larger than the average value of $35 \mathrm{~km}$ which was commonly taken for reference. For example, the average crustal thickness beneath the Canadian Shield is $42 \pm 2 \mathrm{~km}$ [Clowes et al., 1992].

Table 1 summarizes the extensive data set now available for the Archean and Proterozoic provinces of the Canadian Shield. The disposition of these provinces is shown on the map (Figure 1). The average Archean heat flow, based on a total of 57 individual determinations, is $42 \pm 10 \mathrm{~mW} \mathrm{~m}^{-2}, 4 \mathrm{~mW} \mathrm{~m}^{-2}$ less than estimated by Sclater et al. [1980] and by Morgan and Sass [1984]. In a world-wide compilation which does not include the recent Canadian Shield measurements, Nyblade and Pollack [1993] found almost identical values for the average and standard deviation of heat flow values in Archean regions $\left(41 \pm 11 \mathrm{~mW} \mathrm{~m}^{-2}\right)$. The large number of measurements, and the agreement with the new and independent data from Canada, indicate that these values are truly representative of Archean provinces and are unlikely to change with further studies. For these data sets, however, the standard deviation remains quite large, and reflects significant local variations due to the complex assemblage of Archean crust. Such large local variations make the comparison of heat flow data with petrological and geochemical models of the crust difficult. The Early Proterozoic Trans-Hudson Orogen (formely Churchill Province) has an average heat flow of $44 \mathrm{~mW} \mathrm{~m}^{-2}$, slightly higher than the Archean value. This small increase may seem compatible with the idea that continental heat flow decreases with age, but it is in fact due to the high heat production in the Thompson Belt [Guillou-Frottier et al., 1996]. The absence of an age-dependent pattern is confirmed by the Late Proterozoic Grenville province, where the average heat flow is the same as that of the Archean. Heat flow is markedly higher in the Appalachians, but this is again due to higher crustal heat production (Table 1). Jaupart et al. [1982] have shown that when sites on late intrusives are excluded, the average heat flow in the Appalachians is identical to the average values in the Grenville and Superior. Indeed, in their original study, Roy et al. [1968] grouped Grenville sites from the Adirondacks and Appalachians sites in a single heat flow province, because they all satisfied the same heat flow versus heat production relationship. The high Appalachian heat flow is due to a relatively thin enriched upper crustal layer and provides no evidence for mantle heat flow higher than in the Canadian Shield.

\subsection{Bulk Crustal Composition in Precambrian Shields}

In this section, we compare estimates of the average crustal heat production derived from various geochemical and petrological models (Table 2). One approach is to use average values for a set of representative rock types and estimates of their proportions in a crustal column [Haack, 1983; Condie, 1993; Wedepohl, 1991]. A second approach relies on local exposures of terrains of various metamorphic grades, xenoliths suites and a suitable crustal model [Rudnick and Fountain, 1995]. A third approach is to follow a specific genetic model for continental crust formation, for example, in island arcs or in oceanic plateaus. The difficulty lies in assessing the reliability of the crustal model for comparison with heat flow data. The continental crust is a highly heterogeneous mixture of old and young crustal rocks intruded by mafic melts, and hence no simple petrological logic can be followed. The recently recognized importance of mafic intrusions in the continental crust explains why simple petrological models, such as that by Wedepohl [1991], for example, invariably lead to the largest values of crustal radioactivity.

Table 1. Heat Flow Statistics for the Canadian Shield

\begin{tabular}{|c|c|c|c|c|c|}
\hline Province & $\mathbf{N}^{\dagger}$ & $\begin{array}{l}\mathrm{Q} \pm \text { s.d., } \\
\mathrm{mW} \mathbf{m}^{-2}\end{array}$ & $N_{A} \dagger$ & $\begin{array}{c}<A> \pm \text { s.d. } \\
\mu \mathrm{W} \mathrm{m}^{-3}\end{array}$ & Reference \\
\hline Superior (except Abitibi) & 26 & $45 \pm 12$ & 21 & $1.4 \pm 1.2$ & $1,2,6$ \\
\hline Huronian & 5 & $51 \pm 7$ & & & 1 \\
\hline Abitibi & 26 & $37 \pm 7$ & 21 & $0.4 \pm 0.3$ & $1,3,6$ \\
\hline Total Superior (2.7 Ma) & 57 & $42 \pm 10$ & 44 & $0.95 \pm 1.0$ & $1,2,6$ \\
\hline Churchill (Trans-Hudson) (1.8 Ma) & 30 & $44 \pm 12$ & 20 & $0.6 \pm 0.4$ & $4,5,7$ \\
\hline Grenville (1.0 Ma) & 30 & $41 \pm 11$ & 17 & 0.8 & 1,2 \\
\hline Norwegian Shield (1.0 Ma) & 25 & $45 \pm 8$ & 25 & 1.6 & \\
\hline Appalachians (0.4 Ma) & 79 & $57 \pm 13$ & 50 & $2.6 \pm 1.9$ & 8,9 \\
\hline
\end{tabular}

References: 1, Pinet et al. [1991, and references therein]; 2, Guillou-Frottier et al.,[1995, and references therein]; 3, Guillou et al. [1994]; 4, Drury [1987]; 5, Guillou-Frottier et al. [1996]; 6, Mareschal et al., submitted manuscript; 7, Mareschal et al. [1997]; 8, Birch et al. [1968]; 9, Jaupart et al. [1982].

$\dagger$ Number of determinations.

$\ddagger$ Heat flow (mean and standard deviation). 


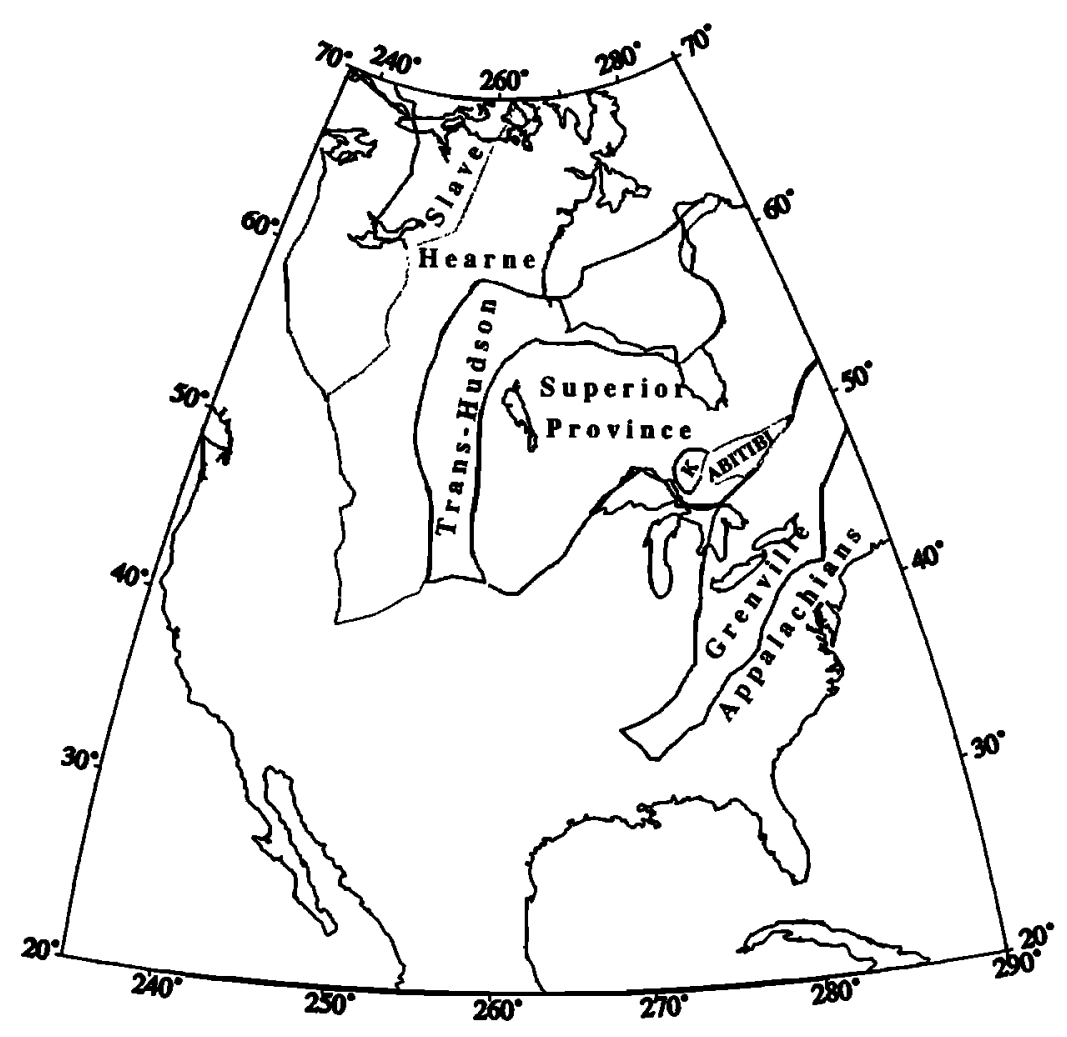

Figure 1. Map showing the Precambrian in North America with the main provinces of the Canadian Shield. $\mathrm{K}$ is the Kapuskasing structural zone. (Adapted from Hoffman [1989].)

Rudnick and Fountain [1995] have recently given a comprehensive compilation of chemical analyses of lower crustal material. Unlike major elements and most trace elements, Uranium and Thorium concentrations exhibit highly skewed distributions. This may be attributed to their highly incompatible characteristics and, in the case of Uranium, to its large mobility. The median values of the distributions are systematically smaller than the mean values. Rudnick and Fountain [1995, p.293] chose to focus on the former values, in order to "minimize the effects of outliers in small sample populations." Another method is to assume that, in a province, concentrations for a given rock type are valid for all the province. Using geological maps, one may determine the areas for each rock type and calculate an areaweighted average. In this case, the "outliers" are rock types which represent a negligible fraction of the crustal assemblage. Using the studies of Ashwal et al. [1987], Fountain et al. [1987], as well as many other published reports, Pinet and Jaupart [1987] and Pinet et al. [1991] applied this method to four well-sampled different granulite facies terrains (the Kapuskasing and Pikwitonei areas of the Superior Province, the Egersund area in southern Norway, and the Ivrea Zone, Italy) and three different amphibolite facies terrains from the Superior Province. For the granulites they found average heat production values tightly clustered around 0.40 $\mu \mathrm{W} \mathrm{m}{ }^{-3}$. Average values for three Australian granulite

Table 2. Crustal Models for Radiogenic Elements

\begin{tabular}{lccccc}
\hline & $\mathrm{U}$, & $\mathrm{Th}$, & $\mathrm{K}_{2} \mathrm{O}$, & $\mathrm{A}$, & \\
& $\mathrm{ppm}$ & $\mathrm{ppm}$ & $\%$ & $\mu \mathrm{W} \mathrm{m}^{-3}$ & Reference \\
\hline Bulk crustal models & & & & & \\
Andesite (whole Earth) & 1.3 & 4.8 & 1.3 & 0.79 & 1 \\
Andesite (Archean) & 1.8 & 3.3 & 0.9 & 0.78 & 2 \\
Global crust/mantle budget & 1.2 & 5.8 & 1.6 & 0.86 & 3 \\
& 1.1 & 4.5 & 1.5 & 0.74 & 4 \\
Archean upper crust & & & & & \\
Shales & 1.5 & 5.7 & 1.8 & 0.95 & 1 \\
Direct sampling & 1.2 & 9.6 & 2.4 & 1.20 & $5-7$ \\
\hline
\end{tabular}

References: 1, Taylor and McLennan [1985]; 2, Condie [1993]; 3, Allegre et al. [1988]; 4, Galer et al. [1989]; 5, Eade and Fahrig [1971]; 6, Ashwal et al. [1987]; 7, Fountain et al. [1987]. 
facies terrains with less data coverage are between 0.2 and $0.4 \mu \mathrm{W} \mathrm{m} \mathrm{m}^{-3}$. For the amphibolite facies terrains, average heat production values are between 1.0 and 1.2 $\mu \mathrm{W} \mathrm{m} \mathrm{m}^{-3}$. These different data sets are consistent. We shall use these values because they come from regions directly relevant to our heat flow data. For example, the Egersund region of the Norwegian Shield, which was once part of a continental block including the Grenville Province, provides a window into the Grenville lower crust.

One useful reference is provided by a global chemical budget for the planet. The continental crust has been formed at the expense of the mantle. Thus one may determine average crust and mantle compositions which are mutually consistent with one another and with the bulk Earth composition [O'Nions et al., 1979; Galer et al., 1989; Allègre et al., 1983, 1988]. These various studies lead to a small range of $0.74-0.86 \mu \mathrm{W} \mathrm{m} \mathrm{m}^{-3}$ for the average heat production for all crustal ages, including rocks younger than Precambrian (Table 2).

The validity of crustal models may be assessed by considering estimates for the upper and lower crust and seismological constraints on crustal structure. The upper crust may be sampled directly, and straight averages have been made over large areas, most notably in the Canadian Shield [Eade and Fahrig, 1971; Shaw et al., 1986]. Others have taken shales as natural averages of the upper crust [Taylor and McLennan, 1985]. These lead to values between 0.95 and $1.20 \mu \mathrm{W} \mathrm{m} \mathrm{m}^{-3}$ for the upper crust, that is, those parts of the crust with metamorphic grade lower than granulite. For the lower crust we take the average heat production of granulite facies terranes, $0.40 \mu \mathrm{W} \mathrm{m}^{-3}$. Using these estimates, we may calculate a bulk crustal average given the proportions of upper and lower crustal material. In the seismic shield models of Holbrook et al. [1992] and Durrheim and Mooney [1991], the lower crust is identified by higher seismic $P$ wave velocities in the range of 6.8-7.2 $\mathrm{km} \mathrm{s}^{-1}$, and makes up 16 out of $45 \mathrm{~km}$ of the crustal column. Taking values between 0.95 and $1.20 \mu \mathrm{W} \mathrm{m}^{-3}$ for the upper crust and $0.40 \mu \mathrm{W} \mathrm{m} \mathrm{m}^{-3}$ for the lower crust, we find bulk Archean crustal averages of 0.76 and $0.91 \mu \mathrm{W} \mathrm{m} \mathrm{m}^{-3}$, respectively. These values are remarkably similar to those deduced from global chemical budgets. Average Archean crust is likely to be poorer in radioelements than younger crust $[R u d-$ nick and Fountain, 1995]. Thus, for compatibility with the global chemical budgets, we are led to select the lower value of $0.76 \mu \mathrm{W} \mathrm{m}^{-3}$ for the average heat production of Archean crust. Over a crustal thickness of $45 \mathrm{~km}$, this implies a crustal heat flow component of 34 $\mathrm{mW} \mathrm{m}{ }^{-2}$. With the average Archean heat flow value of $41 \mathrm{~mW} \mathrm{~m}^{-2}$, this leads to a mantle heat flow of 7 $\mathrm{mW} \mathrm{m}^{-2}$.

The problem with such global reasoning is illustrated by the Canadian Shield, where the average crustal thickness is $42 \mathrm{~km}$. Rudnick and Fountain [1995] suggested that the heat production in the Precambrian crust could be divided into Archean and Proterozoic, with an average heat production of $0.51 \mu \mathrm{W} \mathrm{m} \mathrm{m}^{-3}$ and $0.89 \mu \mathrm{W} \mathrm{m}^{-3}$ respectively. These values would then yield mantle heat flow values of 21,7 , and $4 \mathrm{~mW} \cdot \mathrm{m}^{-2}$, for the Superior, Churchill, and Grenville provinces, respectively. Average heat flow values vary within provinces because of changes in crustal structure and thickness. For example, the average heat flow in the Abitibi subprovince (37 $\mathrm{mW} \mathrm{m} \mathrm{m}^{-2}$ ) is significantly lower than the average for the Superior. This is due to the large amounts of greenstone terranes with low radioactivity which are unaccounted for in most global crustal models. Differences in heat flow and crustal structure between the Norwegian and the Canadian Grenville, that will be discussed later, are another example of this problem.

Averaging over the whole Precambrian allows more reliable comparisons between different data sets because a major fraction of the continental crust is sampled and local heterogeneities are smoothed out. Furthermore, because of its large volume, the average Precambrian crust must be close to the bulk crust of the global chemical budgets. The average Precambrian heat production is $0.84 \mu \mathrm{W} \mathrm{m} \mathrm{m}^{-3}$ according to Rudnick and Fountain [1995], which is indeed within the range of the bulk chemical estimates of $0.74-0.86 \mu \mathrm{W} \mathrm{m}{ }^{-3}$. Following $N y$ blade and Pollack [1993], the average heat flow through Precambrian continents is $46 \mathrm{~mW} \mathrm{~m}^{-2}$, with a negligible error of $\pm 1 \mathrm{~mW} \mathrm{~m}^{-2}$ due to uncertainties in the proportions of Archean and Proterozoic crust (see the discussion by Rudnick and Fountain [1995]). For an average Precambrian crustal thickness of $45 \mathrm{~km}$, the global estimates of crustal heat production lead to values of the mantle heat flow between 9 and $15 \mathrm{~mW} \mathrm{~m}^{-2}$.

Available estimates of bulk crustal heat production are in close agreement for Proterozoic provinces, in contrast to Archean provinces for which there are large discrepancies. For the Canadian Shield, the heat flow data do not support the differences between Archean and Proterozoic crust suggested by some geochemical models. Because the mantle heat flow is a small residual value, it is sensitive to even small errors on the crustal heat production estimates. To ascertain our estimates, we have looked in greater detail at the relationship between heat flow and local crustal structure.

\subsection{Heat Flow in the Eastern Canadian Shield}

A systematic study of the Canadian Shield has led to a detailed heat flow map of the Archean Abitibi subprovince and its boundaries with the Kapuskasing structural zone and the younger Grenville province [Pinet et al., 1991; Guillou et al., 1994: Guillou-Frottier et al., 1995]. Heat flow increases systematically from the Grenville front to the Kapuskasing uplift over a distance of $\approx 500 \mathrm{~km}$. There is also a sharp drop of about $20 \mathrm{~mW} \mathrm{~m} \mathrm{~m}^{-2}$ over a distance of $70 \mathrm{~km}$ across the Ivanhoe Lake fault, which separates the Abitibi from 
the Kapuskasing uplift. This demonstrates that these variations of heat flow are of crustal origin (Figure 2). The long-wavelength variation in heat flow is accompanied by an increase in Bouguer gravity. Taken together with seismic results, these two data sets provide constraints that restrict crustal models and the mantle heat flow to a very narrow range. In the Abitibi subprovince, three crustal lithologies dominate: greenstones, tonalite-trondjemite-granodiorite, and granulite facies rocks. Large outcrops of these three lithologies are exposed in the shield, allowing direct measurements of their densities and heat production rates. Guillou et al. [1994] generated a series of crustal models by varying the mantle heat flow, the thicknesses of the three lithological units, their densities, and heat production rates. Only a limited number of models meet the constraints of both gravity and heat flow data within the error limits set at $2 \mathrm{~mW} \mathrm{~m}^{-2}$ for the heat flow and $4 \mathrm{mGal}$ for gravity. These successful models represent the whole set of solutions. The results can be illustrated by a histogram of mantle heat flow values for the models that fit the data within the given error limits (Figure 3). Models could be found to satisfy the data

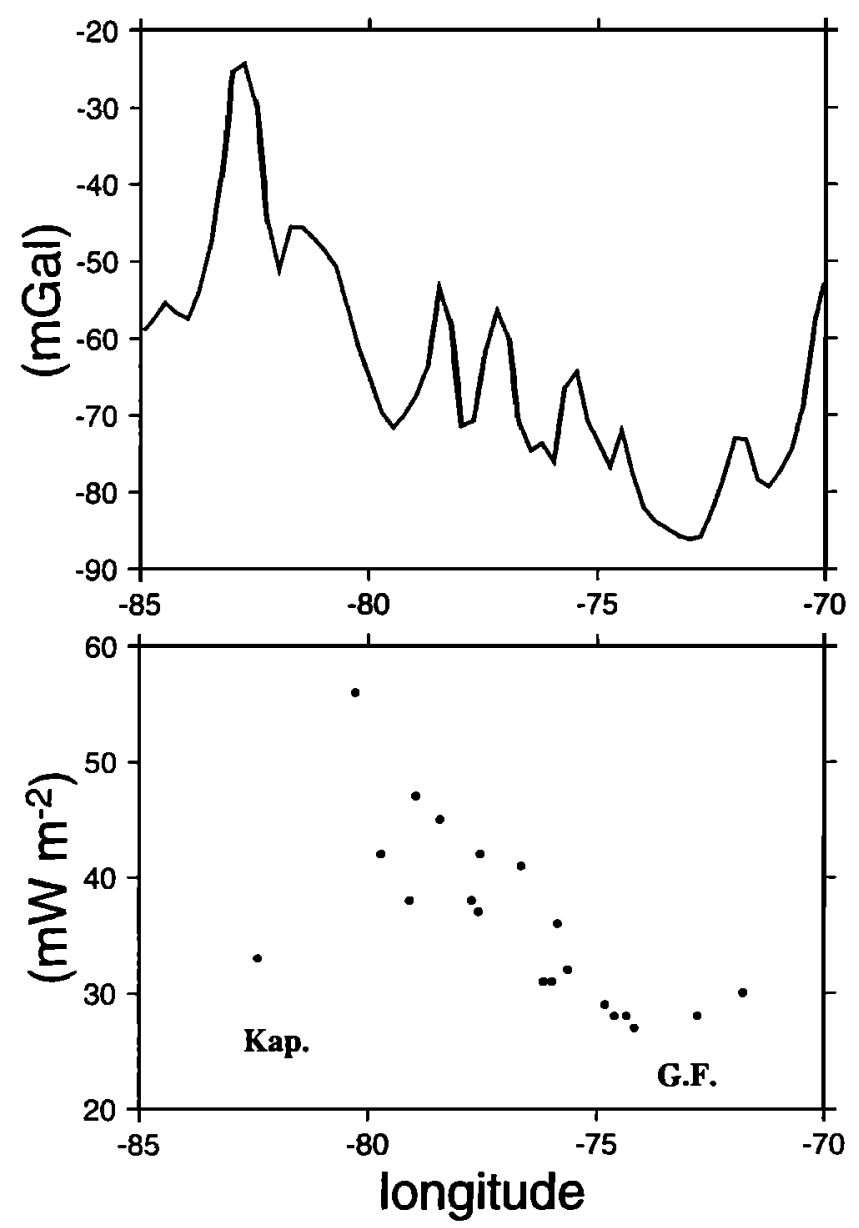

Figure 2. Heat flow and gravity profiles across the Abitibi greenstone belt. The gravity profile is along $49^{\circ} \mathrm{N}$; the heat flow profile includes all values between $48^{\circ}$ and $50^{\circ} \mathrm{N}$.

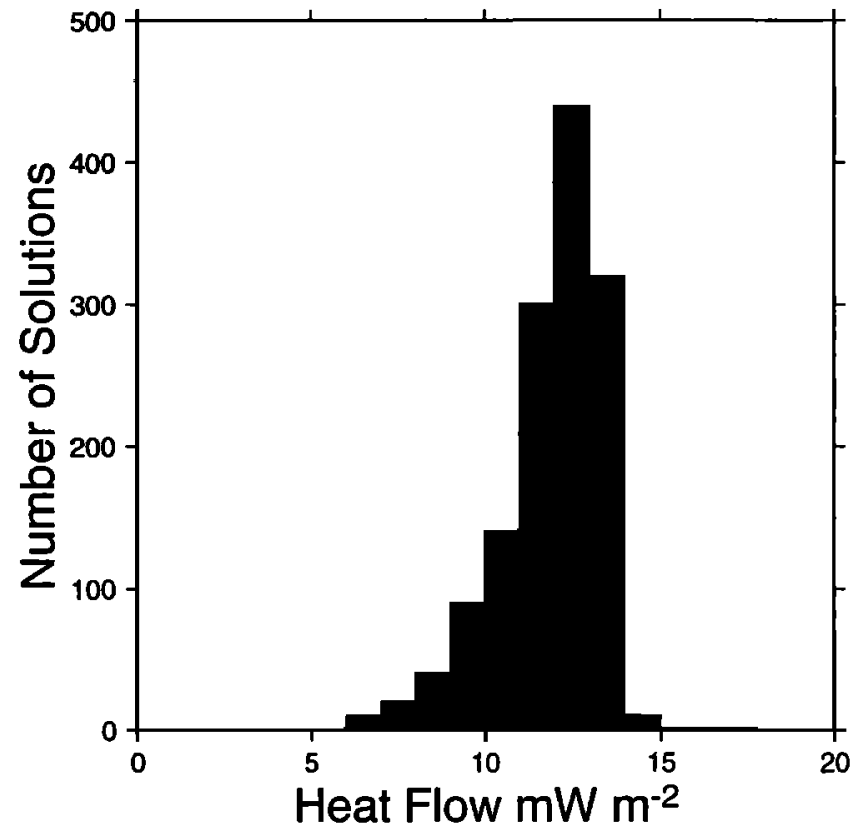

Figure 3. Histogram of mantle heat flow values that yield a model compatible with gravity and heat flow data. The model assumes three crustal layers: greenstone metasedimentary and volcanics, tonalites, and low'r crustal granulites.

only when the mantle heat flow lies between 7 and 15 $\mathrm{mW} \mathrm{m} \mathrm{m}^{-2}$. The average and most probable values are 12 and $13 \mathrm{~mW} \mathrm{~m}^{-2}$, respectively. The value for the Abitibi is within the range of the global Precambrian models.

This result has been derived from a self-consistency argument over a large data set. Values of heat production for the upper and lower crust were not fixed but were left to vary. Thus, for example, fixing the heat production value of lower crustal assemblages at a small value of $0.2 \mu \mathrm{W} \mathrm{m}^{-3}$, say, requires changing all the other variables.

\subsection{Low Heat Flow Regions of the Canadian Shield}

The validity of the mantle heat flow estimate may be assessed by considering specific situations. In the Kapuskasing area, a reliable surface heat flow of 33 $\mathrm{mW} \mathrm{m}^{-2}$ was measured in a deep borehole. In the area, granulite facies terranes have been brought to the surface by large thrust faults with low dip angles [Percival, 1994]. Measurements on rock samples from the granulite facies terranes in this area yielded an average heat production rate of $0.40 \mu \mathrm{W} \mathrm{m}^{-3}$ [Ashwal et al., 1987]. Rocks from the borehole used for heat flow determination at Kapuskasing have an average heat production rate of $0.46 \mu \mathrm{W} \mathrm{m}^{-3}$. A lower bound for the crustal heat production is obtained by assuming that the entire crust has the same heat production than the granulites. The crustal thickness in the Kapuskasing area is 
at least $45 \mathrm{~km}$ [Boland and Ellis, 1989; Percival et al., 1989; Wu and Mereu, 1992]. This yields a lower bound of $18 \mathrm{~mW} \mathrm{~m}^{-2}$ for crustal heat production and conse-

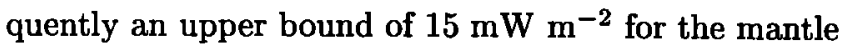
heat flow.

One might argue that low heat flow values are anomalous and cannot be interpreted using an average lower crustal composition. This is not consistent with the observations: low heat flow regions $\left(<32 \mathrm{~mW} \mathrm{~m}^{-2}\right)$ are found throughout the Canadian Shield and correspond to large areas where the mid and lower crusts are exposed. For instance, very low heat flow values have been reported for the Adirondacks or in the lower St. Lawrence valley, more than $500 \mathrm{~km}$ away from the Grenville Front [Birch et al., 1968; Guillou-Frottier et al., 1995]. The heat flow profile across the Abitibi subprovince (Figure 2) shows that the heat flow values are consistently low in the east $\left(27-28 \mathrm{~mW} \mathrm{~m}^{-2}\right)$. The absence of dispersion gives confidence that the error on these values is small. These values are found in a region that extends deeply into the Grenville Province [Guillou et al., 1994, Guillou-Frottier et al., 1995] and is wider than several crustal thicknesses. Heat production rates cannot be uniformly low throughout the large crustal volume sampled. For the estimated $40 \mathrm{~km}$ thick crust, we calculate a lower bound of $16 \mathrm{~mW} \mathrm{~m}^{-2}$ for crustal heat production and a mantle heat flow value of $12 \mathrm{~mW} \mathrm{~m}^{-2}$.

These simple calculations depend on the average heat production of lower crustal material. In the Pikwitonei and Kapuskasing areas, the deepest crustal levels have not been sampled and one could argue that large proportions of mafic rocks poor in radioelements lie in the deep crust. In the Ivrea Zone, Italy, where a crustal cross section extending down to the Moho is exposed, the average heat production of the lower crustal rocks is $0.40 \mu \mathrm{W} \mathrm{m}^{-3}$ [Galson, 1983]. In the southeastern part of the Grenville, low heat flow values of $30-32 \mathrm{~mW} \mathrm{~m}^{-2}$ are found in and around the large Sept-Iles gabbroic/anorthositic massif [Guillou-Frottier et al., 1995]. These exposures correspond to the same structural crustal levels as in the Egersund-Bamble areas of the Southern Norwegian Shield and are made of the same rock types. The extensive Norwegian data set leads to a reliable estimate of $0.40 \mu \mathrm{W} \mathrm{m}{ }^{-3}$ for heat production in the granulite-facies crust [Pinet and Jaupart, 1987]. The crust below these two areas must be made of the same granulite-facies material because there are no thrust faults. The Egersund heat flow value is 21 $\mathrm{mW} \mathrm{m}{ }^{-2}$ [Swanberg et al., 1974]. For comparison with the Sept-Iles value, it must be corrected for the effects of Pleistocene glaciation, which leads to $24-26 \mathrm{~mW} \mathrm{~m}^{-2}$. The heat flow difference of $\approx 6 \mathrm{~mW} \mathrm{~m}^{-2}$ is associated with $\approx 14 \mathrm{~km}$ difference in crustal thickness between Southern Norway [Pinet and Jaupart, 1987] and the Sept-Iles area. This implies an average heat production of about $0.43 \mu \mathrm{W} \mathrm{m}{ }^{-3}$, not significantly different from our estimate of $0.40 \mu \mathrm{W} \mathrm{m}^{-3}$, as the errors on heat flow and crustal thickness are about $\pm 2 \mathrm{~mW} \mathrm{~m}^{-2}$ and $\pm 2 \mathrm{~km}$, respectively. In the Egersund, the presence of large amounts of mafic rocks in the deep crust is ruled out by gravity data [Smithson and Ramberg, 1979].

\section{Mantle Heat Flow and Lithosphere Thickness}

\subsection{Small-Scale Convection Beneath the Lithosphere}

In a study of the thermal and dynamical stability of continents, Doin et al. [1997] have considered the supply of heat to the base of the lithosphere to balance the conductive heat flow and the long-time survival of a thick lithosphere in an actively convecting system. They have shown that it is necessary to invoke both a compositional density contrast and a viscosity contrast between the lithosphere and the convecting mantle. Both types of contrasts are produced simultaneously by basalt extraction. The dehydration of the solid residue increases its viscosity [Pollack, 1986; Hirth and Kohlstedt, 1996]. Partial melting depletes the mantle in incompatible elements, implying low residual uranium and thorium concentrations and hence small radiogenic heat production. Support for the existence of a compositional density contrast comes from the study of geoid anomalies [Turcotte and McAdoo, 1979; Doin et al., 1996].

In eastern Canada the observations do not indicate significant variations of the mantle heat flow beneath lithospheres of various ages, from the Archean to the late Proterozoic. This shows that a stable thermal regime has been reached in old continental lithosphere, which requires a supply of heat at depth (Figure 4). One may entertain three types of physical mechanisms for providing heat to the base of the lithosphere. The lithosphere may first be thought of as a passive body which is rafted on top of oceanic mantle and exchanges heat with it. This model is not compatible with a second class of models which are designed to investigate

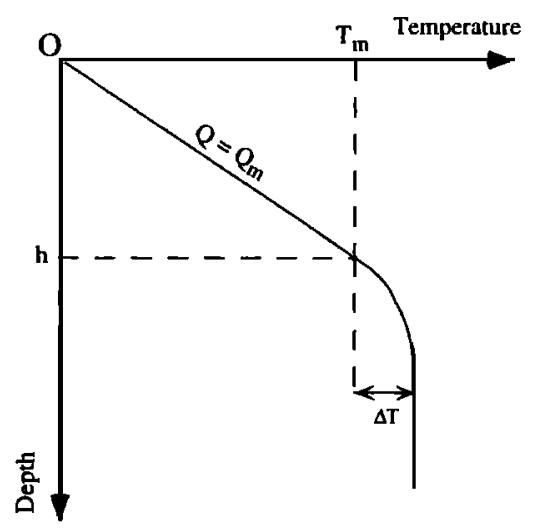

Conductive boundary layer

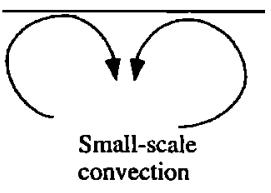

Figure 4. The model lithosphere showing the conductive part and the unstable boundary layer beneath. 
the dynamical consequences of thick, and therefore insulating, continental lithosphere. It may be shown that the continents generate large-scale thermal anomalies in the mantle, which in turn induce convective currents whose dimensions depend on the width of continents [Gurnis, 1988; Zhong and Gurnis, 1993; Lenardic and Kaula, 1996; Guillou and Jaupart, 1995]. In these two types of models, the continental lithosphere has specified characteristics, that is, thickness, rheology, and density, and the problem of what determines them is not addressed. A difficulty is that it is not possible to study the continental problem independently of convection through the whole mantle. A third mechanism to provide heat is small-scale convection, which can be studied extensively and locally. We determine the conditions for small-scale convection to supply the required heat flux at the base of the continental lithosphere and we calculate the thickness of the lithosphere and the temperature of the underlying mantle. We also discuss transient conditions over geological time scales.

\subsection{Small-Scale Convection in Variable Viscosity Liquids}

The Earth's mantle is cooled from the top and has a large temperature difference across its upper boundary layer. This temperature difference implies large viscosity variations. In such conditions, the upper part of the boundary layer is not involved in convective instabilities and remains stagnant [Richter et al., 1983; Fleitout and Yuen, 1984; Buck and Parmentier, 1986; White, 1988; Ogawa et al., 1991; Davaille and Jaupart, 1993a]. Convection is confined to a relatively thin layer where viscosity variations are small, and its characteristics depend on the viscosity function [Jaupart and Parsons, 1985]. Small-scale convection is a feature of many convection models (see the discussion by Davaille and Jaupart [1994]) and may coexist with large-scale convective currents with little modification [Parsons and McKenzie, 1978; Doin et al., 1997].

A recent laboratory study at large viscosity contrasts [Davaille and Jaupart, 1993a] has shown that convection depends solely on variables defined locally in the unstable boundary layer. For a given interior temperature $T_{m}$, the convective heat flux $Q$ does not depend on the surface temperature and is given by

$$
Q=0.47 k_{m}\left(\frac{\alpha g}{\kappa \nu_{m}}\right)^{1 / 3} \Delta T_{v}{ }^{4 / 3}
$$

where $g$ is the acceleration of gravity, $k_{m}, \alpha, \kappa$, and $\nu_{m}$ are thermal conductivity, coefficient of thermal expansion, thermal diffusivity, and kinematic viscosity, respectively. $\Delta T_{v}$ is the convective temperature scale defined as

$$
\Delta T_{v}=-\frac{\mu\left(T_{m}\right)}{(d \mu / d T)\left(T_{m}\right)}
$$

where $\mu$ is viscosity. This equation was derived from scaling arguments and laboratory measurements of con- vection. The laboratory experiments were made for different rates of viscosity variations as a function of temperature and for different viscosity contrasts. Davaille and Jaupart [1993b] have succesfully applied their results to lava lakes, where the effects of convection can be recorded directly. This indicates that the scaling laws are applicable to a wide range of variable viscosity materials. The same scaling laws were obtained by numerical calculations over a large range of Rayleigh numbers and viscosity contrasts (O. Grasset, personal communication, 1997; C.Sotin, personal communication, 1997] and with non-Newtonian fluids with temperature and pressure dependent viscosity [Doin et al., 1997]. In this case, one must take the viscosity parameters at the top of the unstable boundary layer, that is, at the base of the stagnant and conducting lid (Figure 4).

Scalings have also been obtained for the temperature difference across the convective boundary layer $\Delta T$ and the thickness of this boundary layer $\delta$ [Davaille and Jaupart, 1993a]:

$$
\begin{aligned}
\Delta T & \approx 2.2 \Delta T_{v} \\
\delta & \approx 6.2\left(\frac{\Delta T_{m}}{\Delta T}\right)\left(\frac{\alpha g \Delta T}{\kappa \nu_{m}}\right)^{-1 / 3}
\end{aligned}
$$

where $\Delta T_{m}=T_{m}-T_{o}$ is the temperature difference across the stagnant and conductive lid (i.e., the lithosphere). These parameters allow us to calculate the temperature in the well-mixed mantle below the convective boundary layer.

\subsection{The Heat Flux Supplied to the Base of the Lithosphere}

These results can be applied to the continental lithosphere once the rheology of the upper mantle rocks is specified. Karato and Wu [1993] have summarized current knowledge based on laboratory measurements, the solid-state physics of deformation in minerals at high temperature as well as constraints from postglacial rebound studies. The strain rate/stress relation takes the general form:

$$
\dot{\epsilon}=A\left(\frac{\sigma}{\mu_{e}}\right)^{n}\left(\frac{b}{d}\right)^{m} \exp \left(\frac{-(E+P V)}{R T}\right)
$$

where $A$ is a constant, $\mu_{e}$ is the shear modulus, and $b$ is the length of the Burgers vector, $d$ is the grain size, and $E$ and $V$ are the activation energy and volume, respectively. Following Karato and $W u$ [1993], we take $\mu_{e}=8 \times 10^{10} \mathrm{~Pa}, b=5 \times 10^{-10} \mathrm{~m}$, and $d=1$ $\mathrm{mm}$. Values for coefficient $A$ are also taken from their paper. The exponents $n$ and $m$ depend on the creep mechanism. For dry and wet dislocation creep, $n \approx 3.5$ and $\approx 3.0$, respectively, and $m=0$; for diffusion creep, $n \approx 1$ and $m \approx 3$. The effective viscosity $\mu$ is determined by

$$
\mu=A^{-1} \mu_{e}^{n} \sigma_{0}^{1-n}\left(\frac{d}{b}\right)^{m} \exp \left(\frac{E+P V}{R T}\right)
$$


where $\sigma_{0}$ is the second-order stress invariant. Introducing the values of the parameters in (6), we obtain the final relationship:

$$
\mu=C \exp \left(\frac{E+P V}{R T}\right)
$$

where $C$ is a constant for diffusion creep; and $C$ depends on the stress level for dislocation creep. In the present paper, we chose a value of $1 \mathrm{MPa}$ for the stress level due to small-scale convection. However, it will be seen that dislocation creep cannot account for the observed mantle heat flow regardless of the reference stress level chosen. Table 3 gives the parameter values relevant to the upper mantle for four deformation mechanisms: dislocation creep in dry and watersaturated ("wet") olivine, diffusion creep in dry and water-saturated ("wet") olivine. According to Karato and $W u$ [1993], the most likely deformation mechanism deeper than $\approx 200 \mathrm{~km}$ is diffusion creep in rocks containing some water without being saturated. For the subcontinental mantle, therefore, one expects a linear rheology with parameters between those for dry and wet olivine.

To evaluate these results in the context of the heat flow constraints, we first fix the base of the lithosphere at a depth of $250 \mathrm{~km}$. We use values for the relevant physical properties listed in Table 4 . Thermal conductivity depends mostly on temperature for the pressure range of this problem and includes the effects of both phonons and photons. Below the lithosphere, temperatures are larger than $1550 \mathrm{~K}$, and available laboratory measurements indicate a value of thermal conductivity $\approx 3.2 \mathrm{~W} \mathrm{~m}^{-1} \mathrm{~K}^{-1}$ [Schatz and Simmons, 1972; Roy et al., 1981; Schärmeli, 1979]. We return to this question later, but we note that because the convective heat flux depends on $k^{2 / 3}$, it is not very sensitive to the specific value chosen. For a given viscosity law, temperature is the only unknown. Using (1) for the small-scale convection heat flux, we calculate heat flow as a function of temperature (Figure 5). For the purposes of discussion, we consider a range of $10-14 \mathrm{~mW} \mathrm{~m}^{-2}$ for the mantle heat flow. For these values, dry-dislocation creep requires temperatures in excess of $2050 \mathrm{~K}$. The other creep mechanisms require temperatures between 1550 and $1900 \mathrm{~K}$. In the well-mixed oceanic upper mantle,

Table 3. Parameters for Mantle Viscosity Laws

\begin{tabular}{lccc}
\hline Creep Mechanism & $\begin{array}{c}C, \\
\mathrm{~Pa} \mathrm{~s}\end{array}$ & $\begin{array}{c}E, \\
\mathrm{~kJ} \mathrm{~mol}\end{array}$ & $\begin{array}{c}V, \\
\mathrm{~cm}^{3} \cdot \mathrm{mol}^{-1}\end{array}$ \\
\hline Dry diffusion & $5.19 \times 10^{10}$ & 300 & 6 \\
Wet diffusion & $8.55 \times 10^{10}$ & 240 & 5 \\
Dry dislocation & 4.14 & 540 & 20 \\
Wet dislocation & $2.56 \times 10^{2}$ & 430 & 15 \\
\hline
\end{tabular}

The parameters for dislocation creep have been calculated for a reference stress level of $1 \mathrm{MPa}$.
Table 4. Physical Properties of Lithosphere and Upper Mantle

\begin{tabular}{lc}
\hline Parameter & Value \\
\hline Thermal conductivity & \\
Crust + lithosphere, $k_{L}$ & $2.8 \mathrm{~W} \mathrm{~m}^{-1} \mathrm{~K}^{-1}$ \\
Convecting mantle, $k_{m}$ & $3.2 \mathrm{~W} \mathrm{~m}^{-1} \mathrm{~K}^{-1}$ \\
Thermal diffusivity, $\kappa$ & $8 \times 10^{-7} \mathrm{~m}^{2} \mathrm{~s}^{-1}$ \\
Thermal expansion coefficient, $\alpha$ & $4 \times 10^{-5} \mathrm{~K}^{-1}$ \\
Mantle density, $\rho_{m}$ & $3.3 \mathrm{Mg} \mathrm{m}^{-3}$ \\
\hline
\end{tabular}

away from upwellings and subduction zones, the reference isentropic decompression path corresponds to a potential temperature of about $1550 \mathrm{~K}$ [McKenzie and Bickle, 1988]. At $250 \mathrm{~km}$, this predicts a temperature of about $1700 \mathrm{~K}$. The uncertainty on this estimate is probably $\approx 50 \mathrm{~K}$. Seismic tomography results do not indicate that the mantle is hotter beneath continents than oceans [Anderson, 1990]. Thus these considerations rule out dry diffusion creep as a rheology compatible with the heat flux and the mantle temperature. Wet diffusion creep, or a rheology intermediate between dry and wet diffusion creep in olivine, meets the constraints.

We also calculate viscosity values at the same reference depth of $250 \mathrm{~km}$ (Figure 6). Postglacial rebound studies yield an average viscosity for the upper manthe beneath the lithosphere which is between $10^{21}$ and $5 \times 10^{21} \mathrm{~Pa} \mathrm{~s}$, according to various authors [McConnell, 1968; Peltier, 1981; Nakada, 1983]. For diffusion creep, viscosity increases with depth through the upper mantle along an isentropic temperature profile by a factor of about 20. For dislocation creep, this increase is several orders of magnitude larger. Thus the average upper mantle viscosity values imply that the local viscosity at the base of the lithosphere should lie between about $10^{20}$ and $5 \times 10^{20} \mathrm{~Pa}$ s for diffusion creep and should be less than $10^{18} \mathrm{~Pa}$ s for dislocation creep. Figure 6 shows that mantle heat flow values for diffusion creep are compatible with the postglacial rebound constraints.

The above results are modified only slightly if other values for the physical properties are selected within their probable ranges. The activation volume has a negligible effect on the results if it is varied between the bounds quoted by Karato and $W u$ [1993].

In conclusion, the mantle heat flow values derived in section 2 may be supplied to the base of the continental lithosphere if the deformation mechanism of the upper mantle is diffusion creep. The predictions for wet diffusion creep are in agreement with all available constraints, that is, viscosity values from postglacial rebound studies, the likely range of continental mantle temperatures.

\subsection{Thickness of the Lithosphere}

In steady state conditions, the mantle heat flow is transported by conduction through the lithosphere. 


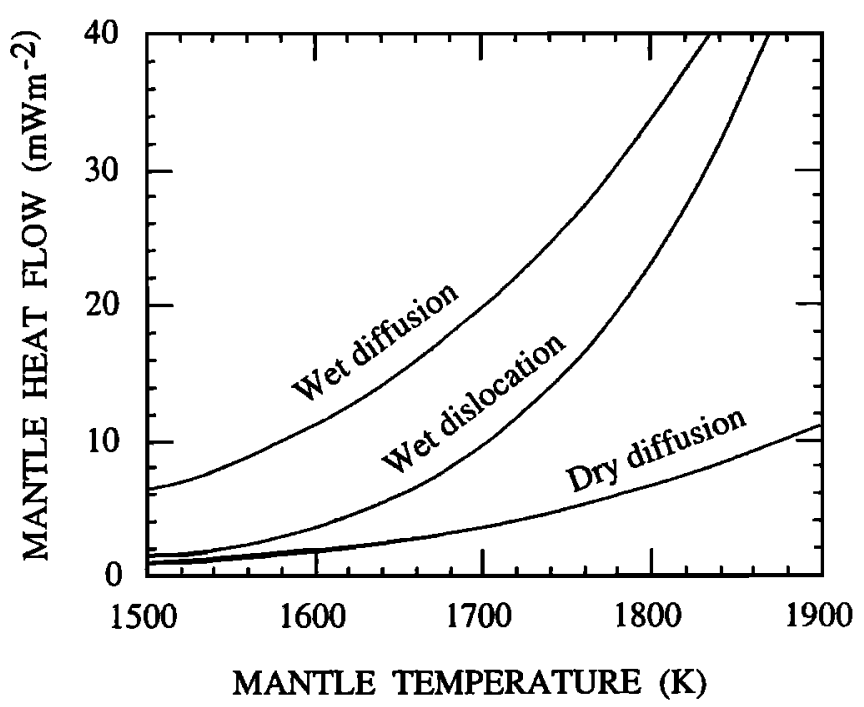

Figure 5. Mantle heat flow supplied by small-scale convection as a function of mantle temperature at 250 $\mathrm{km}$ depth. Three different creep laws have been used, with parameters given in Tables 3 and 4 .

Thus one may calculate the vertical temperature profile from the surface downwards using heat flow constraints. We may write the temperature in the mantle part of the lithosphere as follows:

$$
T(z)=T_{c}+\int_{z_{c}}^{z} \frac{Q_{m}}{k_{L}} d z
$$

where the mantle conductivity $k_{L}$ depends on temperature. $T_{c}$ is the temperature at the Moho discontinuity, which depends on the surface heat flow $Q_{s}$, on the distribution of radiogenic heat production in the crust and on the values of conductivity of crustal rock types. Detailed calculations for specific cases [Pinet et al., 1991] yield for $T_{c}$ a value of $673 \pm 100 \mathrm{~K}$. Throughout most of the following, we shall take a value of $673 \mathrm{~K}$. We shall neglect heat generation in the mantle part of the lithosphere because it is likely to be very small.

The value of thermal conductivity $k_{L}$ is critical. Thermal conductivity depends mostly on temperature for the pressure range of this problem and includes the effects of both phonons and photons. Thermal conductivity has a typical average value of $2.5 \mathrm{~W} \mathrm{~m}^{-1} \mathrm{~K}^{-1}$ in the continental crust [Clauser and Huenges, 1995] and is expected to increase in the mantle part of the lithosphere. We have used the following equation for the mantle thermal conductivity as a function of temperature:

$$
k_{L}(T)=\frac{1}{0.174+0.000265 T}+0.36810^{-9} T^{3}
$$

where $T$ is in kelvins [Doin and Fleitout, 1996]. This equation is consistent with the available laboratory data [Schatz and Simmons, 1972; Schärmeli, 1979; Roy et al., 1981] and gives an average conductivity value of $3.0 \mathrm{~W} \mathrm{~m}^{-1} \mathrm{~K}^{-1}$ in the $273-1600 \mathrm{~K}$ temperature range. It may be emphasized that, because of (8) for temperature, the average conductivity value does not lead to the average geotherm. The uncertainty on thermal conductivity is difficult to assess. The difficulty of making measurements at high temperatures implies a small data set [Schatz and Simmons, 1972]. Other sources of uncertainty are due to anisotropy [Schärmeli, 1979] and to the fact that measurements are made on individual minerals, which makes the evaluation of the bulk property of the polycrystalline mantle assemblage difficult. It is therefore useful to make direct large-scale estimates on the oceanic lithosphere. This may be achieved using the systematics of heat flow, depth and geoid anomalies in young ocean basins [Lister, 1982; Gibert and Courtillot, 1990; Doucouré and Patriat, 1992] and leads to bulk conductivity values in the range of $2.7-2.9$ $\mathrm{W} \mathrm{m} \mathrm{m}^{-1} \mathrm{~K}^{-1}$. These are significantly lower than frequently assumed values, as already emphasized by Lister [1982], and are compatible with the predictions of (9). We found that differences are negligible between calculations with a conductivity given by (9) and with a constant conductivity value of $2.8 \mathrm{~W} \mathrm{~m}^{-1} \mathrm{~K}^{-1}$. From this discussion we estimate that the uncertainty on conductivity at high temperature is less than $20 \%$.

With these values, we may calculate a geotherm for a given value of mantle heat flow. We shall require that the same heat flow is supplied by small-scale convection beneath the lithosphere, using (1) and viscosity function (7), which provides a second relationship between temperature and depth. The two temperature versus depth curves intersect at a given temperature and depth (Figure 7). This defines the stable solution, that is, such that the conductive heat flux across the lithosphere is supplied by small-scale convection underneath it. The characteristics of small-scale convection are evaluated

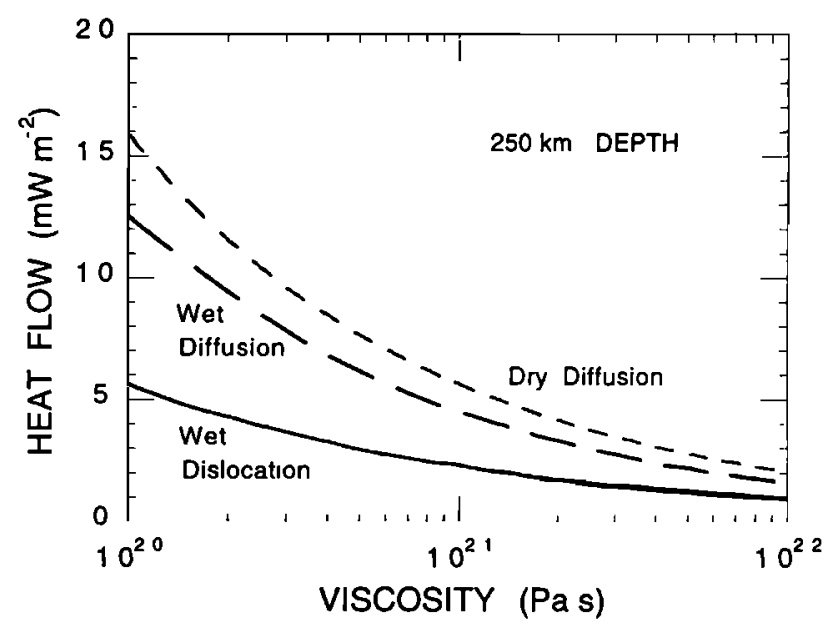

Figure 6. Mantle viscosity as a function of mantle heat flow for a depth of $250 \mathrm{~km}$ for the same cases as Figure 5. 


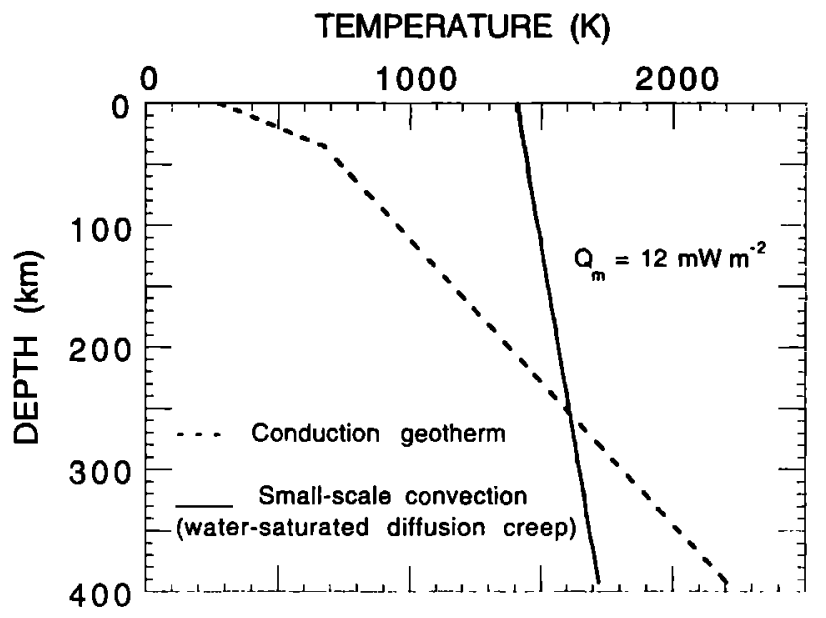

Figure 7. Temperature profile through the conductive lithosphere for a mantle heat flow of $12 \mathrm{~mW} \mathrm{~m}^{-2}$. Also shown is the relationship between depth and temperature which is required for small-scale convection to supply the same heat flux.

for the values of temperature and pressure at the base of the conduction region. Thus one must add the unstable boundary layer in order to reach the fully convecting mantle (Figure 4). For our purposes it is more useful to use the purely conductive upper layer because it is this layer which survives over large time scales.

Figure 8a shows the lithosphere thickness as a function of mantle heat flow for both dry and wet diffusion creep. For a mantle heat flow value fixed at $13 \mathrm{~mW} \mathrm{~m}^{-2}$ (see above), we find a range of $240-320 \mathrm{~km}$ due to the uncertainty on the water content of mantle minerals. A recent study [Hirth and Kohlstedt, 1996] suggests that the water contents of mantle minerals are sufficient to bring the creep parameters close to water saturation values. In this case, the "wet" values adopted in this paper would be closest to reality. The numerical results are sensitive neither to the values of thermal conductivity adopted (Figure 8b) nor to the specific Moho temperature selected (Figure 8c). Changing the Moho temperature by $100 \mathrm{~K}$ changes the lithosphere thickness by less than $25 \mathrm{~km}$. The effect of increasing the Moho temperature, for example, is compensated by the larger values of mantle conductivity.

The range of lithospheric thicknesses could be narrowed down by adding constraints from other geophysical studies, but this is outside the scope of this paper. For a given creep law, the lithosphere thickness is sensitive to the mantle heat flow value (Figure 8a). In contrast, the basal temperature does not change much when the mantle heat flow is varied within its probable range (Figure 9). The reason for this behavior is that viscosity is very sensitive to temperature and much less so to pressure because of the relatively small value of the activation volume. For example, for wet diffusion creep, the basal temperature is constrained to lie between $1615 \mathrm{~K}$ and $1635 \mathrm{~K}$ for mantle heat flow values
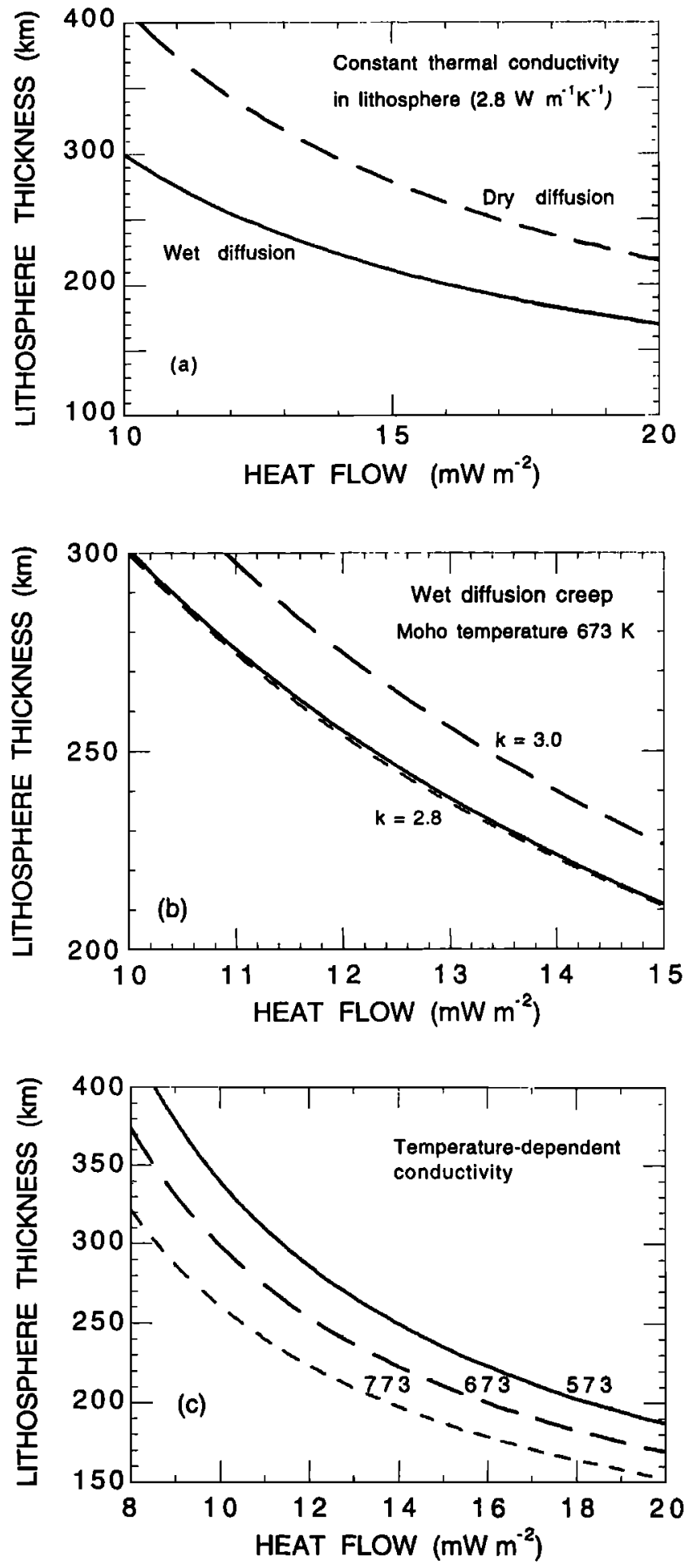

Figure 8. (a) Lithosphere thickness as a function of mantle heat flow for diffusion creep. The Moho temperature is taken to be $673 \mathrm{~K}$. (b) Lithosphere thickness as a function of mantle heat flow for "wet" diffusion creep law. The thermal conductivity of the lithosphere is taken to be $2.8 \mathrm{~W} \mathrm{~m}^{-1} \mathrm{~K}^{-1}$ (solid curve), 3.0 $\mathrm{W} \mathrm{m} \mathrm{m}^{-1} \mathrm{~K}^{-1}$ (long dashes), and fully temperature dependent (small dashes). (c) Lithosphere thickness as a function of mantle heat flow for wet diffusion creep and for three different Moho temperatures (in kelvins). Thermal conductivity varies with temperature in the lithosphere. 


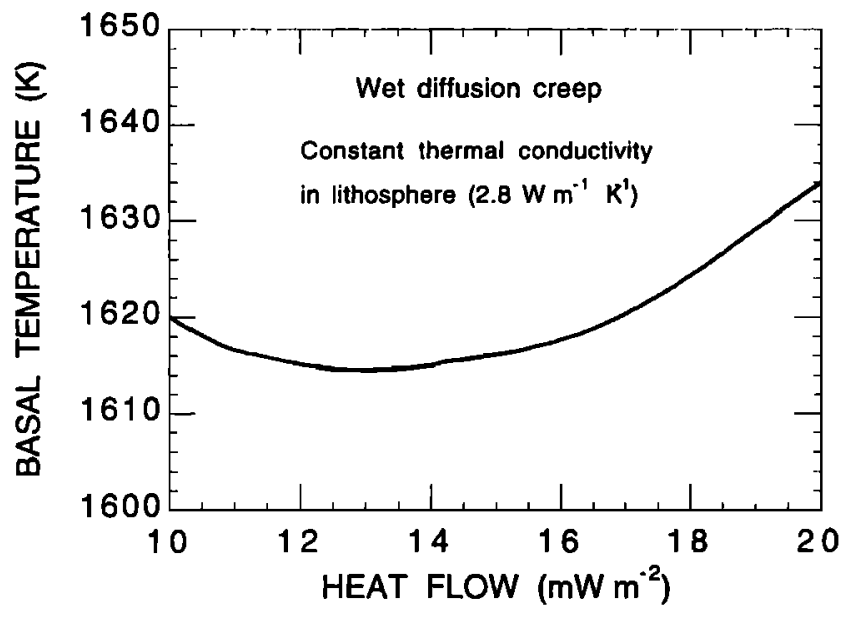

Figure 9. Temperature at the base of the lithosphere as a function of mantle heat flow for small-scale convection in the wet diffusion creep regime.

in the range of $10-20 \mathrm{~mW} \mathrm{~m}^{-2}$. The thickness of the unstable boundary layer is about $40 \mathrm{~km}$, and the temperature difference across it is about $170 \mathrm{~K}$. Thus, for the same range of mantle heat flow values and for a given rheology, the temperature in the fully convecting mantle beneath continents is predicted to be about $1770 \mathrm{~K}$ at a depth of $300 \mathrm{~km}$.

In the mantle, temperature differences should by definition be restricted to the lithospheres and their convective boundary layers. Over large horizontal distances between continents and oceans, however, there may be temperature differences due to large-scale convective circulation [Zhong and Gurnis, 1993; Guillou and Jaupart, 1995]. Direct temperature estimates in the convecting oceanic mantle can be derived from the cooling behavior of the oceanic lithosphere and from the amount and composition of mid-ocean ridge theoleiites. McKenzie and Bickle [1988] have proposed a mean potential temperature of $1553 \mathrm{~K}$. Uncertainties in this estimate are difficult to quantify, in particular because the temperature of mid-ocean ridge basalt sources is not uniform. For the sake of discussion, we consider an uncertainty of $\pm 50 \mathrm{~K}$. At the depth of $300 \mathrm{~km}$, temperatures prevailing in the well-mixed oceanic mantle are probably in the range of 1690 and $1790 \mathrm{~K}$. This range encompasses our estimate for a diffusion creep mechanism. Thus a low heat flow through continents, which suggests an insulating effect, does not necessarily imply an anomalously high mantle temperature.

\section{Stability of Continental Lithosphere}

\subsection{Lithosphere Evolution}

It has been suggested that the continental lithosphere is stabilized by both its intrinsic density difference with respect to oceanic mantle and by its enhanced viscosity [Jordan, 1978; Doin et al., 1997]. This implies a compositional and a thicker thermal lithosphere. We shall address the question of the thickness of this thermal lithosphere. We shall first assume that the mantle temperature remains constant through time. For this discussion we consider the case of wet diffusion creep, because it provides the most satisfactory fit to the observations. Conclusions would be quantitatively different, but not qualitatively, for dry diffusion rheology.

For a given mantle rheology, we determine $h$ the thickness of a thermally stable lithosphere, as a function of mantle temperature $T_{m}$ (Figure 10). Initially, the lithospheric thickness is fixed by compositional buoyancy. The equilibrium curve has a minimum for $T_{m}=$ $T_{\text {inf }}$ and $h=h_{c}$. Above the curve, small-scale convection provides more heat than can be transported by conduction. This may have two consequences depending on the behavior of the lithosphere. Small-scale convection may heat the base of the lithosphere and thin it, which leads to a steady state regime (Figure 11). Alternatively, if the lithosphere cannot be thinned, because, for instance, of its large compositional contrast, the mantle will heat up. Below the equilibrium curve, small-scale convection cannot supply enough heat to balance conductive heat loss: the lithosphere thickens by cooling. It is unlikely that the initial conditions at the base of the lithosphere are along the equilibrium curve, and we discuss the various possibilities illustrated schematically in Figure 11. If the basal conditions are initially above the curve, a steady state can be achieved through heating and thinning. Below the equilibrium curve, if the initial temperature is above $T_{\mathrm{inf}}$, there are two possibilities. For $h \leq h_{c}$, the lithosphere can thicken by cooling and basal conditions tend toward the equilibrium curve. If, on the other hand, $h \geq h_{c}$, the lithosphere also thickens due to cooling, but this drives the basal conditions away from the equilibrium curve and the lithosphere thickens indefinitely.

For the wet diffusion case, which meets all available constraints (see above), the minimum basal tempera-

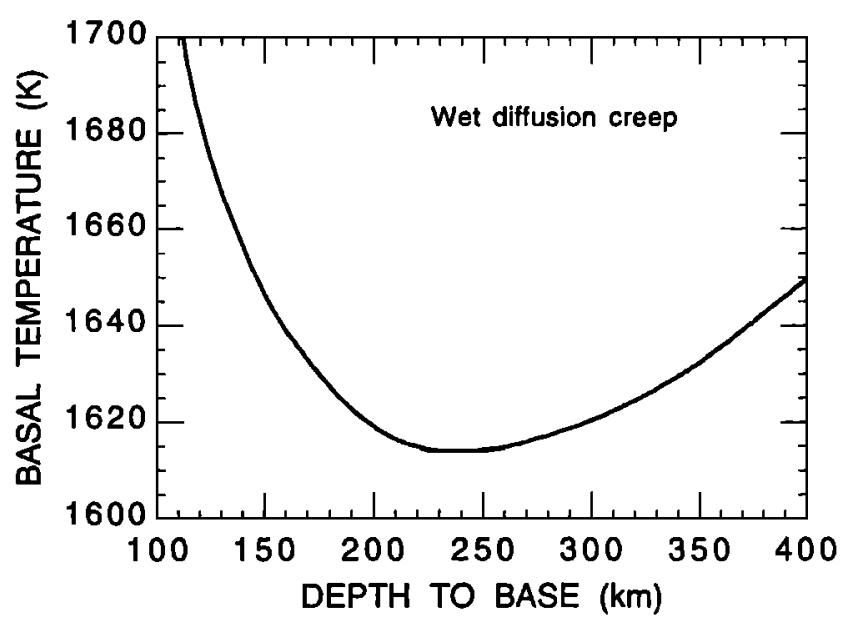

Figure 10. Conditions at the base of the lithosphere in the wet diffusion creep regime. Each point of the curve corresponds to a different heat flow. 
ture corresponds to a mantle heat flow of $13 \mathrm{~mW} \mathrm{~m}^{-2}$ and a thickness of $240 \mathrm{~km}$. The stability considerations developed above imply that the stable mantle heat flow beneath continents must be larger than $13 \mathrm{~mW} \mathrm{~m}^{-2}$ and that the compositional lithosphere must be thinner than $240 \mathrm{~km}$. The condition of stability and the estimates of mantle flow from the Canadian Shield give the restricted range of $13-15 \mathrm{~mW} \mathrm{~m}^{-2}$ for a stable regime. For dry diffusion, the same reasoning leads to a minimum mantle heat flow of $17 \mathrm{~mW} \mathrm{~m}^{-2}$ and a maximum lithosphere thickness of $250 \mathrm{~km}$. This rheology is therefore not compatible with our estimates of mantle heat flow in the Canadian Shield. We had already rejected it on the basis of its requirements for the mantle temperature.

\subsection{Time-Dependent Conditions}

The lithosphere moves with respect to the convecting mantle, and its base is likely to be subjected to variations in temperature and heat flux. In this case, the definition of the lithosphere must be understood as a time average. Two different types of time variations must be considered: short-time scale fluctuations due to hot spots or to hotter regions of the mantle, and longtime scale variations due, for example, to the rundown of mantle radioactivity. The effect of time variations in the lower boundary conditions are examined in the Appendices. The main point is that because the continental lithosphere is much thicker that its oceanic counterpart, rapid temperature fluctuations are smoothed out, and the measured value of surface heat flow only records variations over long time scales. If we assume that the lithosphere thickness $\mathrm{L}$ is $240 \mathrm{~km}$, which is our preferred solution, for a diffusivity of $10^{-6} \mathrm{~m}^{2} \mathrm{~s}^{-1}$ the characteristic diffusion time $\tau=L^{2} / \kappa$ is very large $\left(\approx 2 \times 10^{9}\right.$ years). This implies that the surface heat flow only records changes of basal temperature and heat flux over periods longer than about 1 Gyr (Appendix A).

The lithosphere must be stable to fluctuations of mantle temperature, even though the effects are not recorded by the surface heat flow. If, at some arbitrary time, basal conditions are in equilibrium on the curve (Figure 11), changing mantle temperature might drive the lithosphere away from equlibrium. For $h \leq h_{c}$, a new steady state can be reached (Figure 11). For $h \geq h_{c}$ the fluctuations drive the lithosphere away from the curve.

One may also consider long-term changes of mantle temperatures due to secular cooling. According to measurements of the soruce temperatures of fossil mantle melts, the mantle temperature has been decreasing at a rate of about $100 \mathrm{~K} / \mathrm{Gyr}$ for at least $2 \mathrm{Ga}$ [Nisbet et al., 1993; Abbott et al., 1994]. Such a temperature decrease remains uncertain, because it is based on a simple parameterization of melting, but it is unlikely that the mantle has been heating over the last few billion years.
Such temperature changes are monotonous and imply significant changes for heat flow due to small-scale convection (Figure 5). Consider that, at some initial time, a continental lithosphere stabilizes by basalt extraction. We assume that this initial lithosphere is at equilibrium, with its basal temperature along the equilibrium curve of Figure 11. As the mantle temperature decreases, the lithosphere must thicken to remain on the equilibrium curve. The initial thickness is therefore constrained to be smaller than the maximum value $\left(h_{c} \leq 240 \mathrm{~km}\right.$ for wet diffusion creep). Another argument reinforces this conclusion. We use the calculations of Appendix B and approximate the variation of heat flow by an exponential decay with a characteristic time of $\approx 3 \times 10^{9}$ years. Over the large time scales of interest here, conductive adjustment of lithosphere thickness can be considered rapid (Appendix C). If the lithosphere was thick initially, its diffusive time scale is large and the present-day mantle heat flow must be smaller than the estimate derived from surface measurements. For $h=200 \mathrm{~km}$ the true mantle heat flow today is less than $80 \%$ of the surface estimate (Figure 12). This displaces lithospheric conditions away from the equilibrium curve. This argument suggests that the lithosphere has thickened with time and that it is presently near the maximum stable thickness.

\section{Conclusions}

The Superior Province is the largest Archean craton. The analysis of the Canadian Shield heat flow data cannot be generalized to other shield areas without careful consideration of the local variations in crustal composition and structure. Nevertheless, models of heat flow and cratonic evolution must at least be consistent with the Canadian Shield data.

From global chemical budgets and a detailed study of crustal structure in the Abitibi province of the Superior Province, the mantle heat flow beneath the Canadian Shield is constrained to be between 7 and $15 \mathrm{~mW} \mathrm{~m}^{-2}$. The requirement that the lithosphere is thermally stable because of small-scale convection implies that the mantle heat flow cannot be less than $13 \mathrm{~mW} \mathrm{~m}^{-2}$. One therefore arrives at a rather tight range of 13-15 $\mathrm{mW} \mathrm{m}{ }^{-2}$ for the mantle heat flow and $200-250 \mathrm{~km}$ for the thickness of the conductive lithosphere. For the total boundary layer beneath the Canadian Shield, which includes a layer unstable to small scale convection, the range is about $240-290 \mathrm{~km}$. This is the depth below which one should expect small temperature differences between cratons and oceanic basins. These estimates depend somewhat on the values of a host of physical properties, such as thermal expansion, thermal conductivity, as well as the parameters of the creep law, but the agreement between totally independent estimates is encouraging. One point of this paper is that one cannot determine the thickness of the lithosphere with a sin- 
gle method. Seismic tomography cannot separate between the conductive and convective boundary layers. The downward continuation of geotherms does not allow determination of the base of the lithosphere without a boundary condition, that is, a convective model specifying how the mantle heat flow is maintained. Within the framework of a given mechanism of convective heat transport, a given value of the mantle heat flow implies a tightly constrained value for the mantle temperature.

The model requires the presence of a compositional boundary layer which is mechanically stable, that is, which does not thin appreciably due to shear stresses associated with large-scale convective motions [Doin et $a l ., 1997]$. There is no reason to assume that temperature is horizontally uniform within this layer, nor that its base lies at the same depth across the whole North American continent. Across the Canadian Shield and in the Appalachians the different crustal compositions imply different Moho temperatures [Pinet et al., 1991; J.C. Mareschal et al., Heat flow and deep structure near the edge of the Canadian Shield, submitted to Canadian Journal of Earth Sciences, 1998] (hereinafter referred to as Mareschal et al., submitted manuscript, 1998). As shown by Figure 9, such differences imply a correlation between geological age and lithosphere thickness, although mantle heat flow is the same.

\section{Appendix A: Periodic Changes of Boundary Conditions at the Base of the Lithosphere}

If the lithosphere moves over hot spots, it experiences variations of temperature and heat flux at its base. If the variation in heat flow at the base of the lithosphere is approximated by a periodic function, $Q_{L}(t)=\Delta Q \cos (\omega t)$. For constant surface temperature the solution to the heat equation yields the surface heat flow:

$$
Q_{0}(t)=\frac{1}{2} \frac{\cos \left(\omega t-\sqrt{\frac{\omega \tau}{2}}\right) \exp \sqrt{\frac{\omega \tau}{2}}+\cos \left(\omega t+\sqrt{\frac{\omega \tau}{2}}\right) \exp }{\cosh ^{2} \sqrt{\frac{\omega \tau}{2}}-\sin ^{2} \sqrt{\frac{\omega \tau}{2}}}
$$

where $\tau=L^{2} / \kappa$ and $\kappa$ is the thermal diffusivity. The series is made of exponentially decreasing terms that can be neglected for large $t$ when the effect of the initial condition has decayed. For $\omega \tau \gg 1$, that is, the period of the heat flow variation is much smaller than the heat conduction time for the lithosphere, the surface heat flow variation is $\mathcal{O}(\exp (-\sqrt{\omega \tau / 2}))$ and can be neglected.

If a periodic change in temperature $\Delta T \cos \omega t$ is assumed at the lower boundary, the solution of the heat equation gives for the surface heat flow: where $K$ is the thermal conductivity. For $\omega \tau \gg 1$, that is, the period of the heat flow variation is much smaller than the heat conduction time for the lithosphere, the surface heat flow variation is $\mathcal{O}(\exp (-\sqrt{\omega \tau / 2}))$ and can be neglected.

For example, if the period of fluctuations is one half of the heat conduction time, the amplitude of heat flow variations is less than $9 \%$ of the variation at depth. Thus, for the purposes of this study, one only need discuss variations over periods longer than $\tau / 2$.

\section{Appendix B: Secular Decrease in Heat Flow}

The secular decrease in heat flow from the mantle $Q_{m}$ due to the rundown of radioactive elements can be approximated by

$$
Q_{m}(t)=Q_{m} \exp (-\lambda t)
$$

where $t$ is time and the decay constant $\lambda$ is of the order of $3 \times 10^{-10} \mathrm{yr}^{-1}$. Because of the lithsophere thickness, the decrease in surface heat flow will lag behind the decrease in heat flow at the base of the lithosphere. This effect can be calculated from the solution of the heat equation. The surface heat flow is obtained as

$$
\begin{gathered}
\frac{Q_{0}(t)}{Q_{m}}=\frac{\exp (-\lambda t)}{\cos \sqrt{(\lambda \tau)}} \\
+\pi \sum_{n=0}^{\infty} \frac{(-)^{n}(2 n+1) \exp \left[-(2 n+1)^{2} \pi^{2} t / 4 \tau\right]}{\lambda \tau-(2 n+1)^{2} \pi^{2} / 4}
\end{gathered}
$$

$$
\frac{Q_{0}(t)}{K \Delta T / L}=\frac{\sqrt{\omega \tau}\left[\cos \left(\omega t-\sqrt{\frac{\omega \tau}{2}}-\frac{\pi}{4}\right) \exp \sqrt{\frac{\omega \tau}{2}}-\cos \left(\omega t+\sqrt{\frac{\omega \tau}{2}}+\frac{\pi}{4}\right) \exp -\sqrt{\frac{\omega \tau}{2}}\right]}{\sinh ^{2} \sqrt{\frac{\omega \tau}{2}}+\sin ^{2} \sqrt{\frac{\omega \tau}{2}}}+\sum \cdots
$$




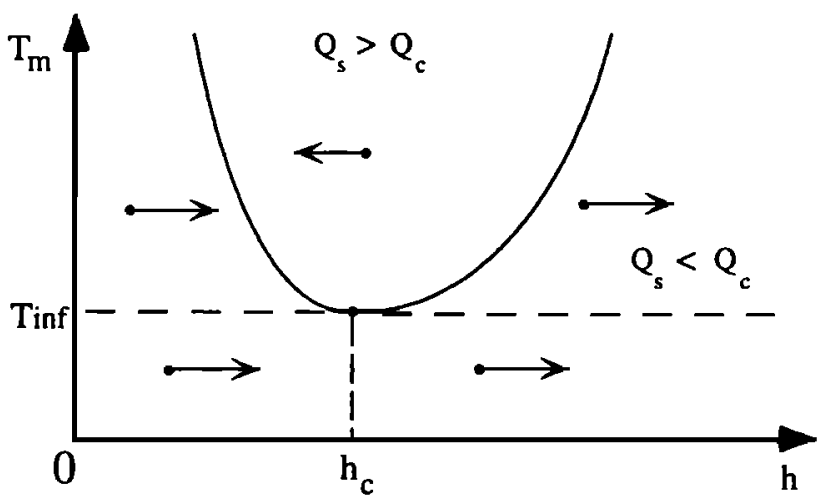

Figure 11. Relationship between mantle temperature and lithosphere thickness. Above the curve, the heat flow supplied by small-scale convection exceeds the heat conducted across the lithosphere. Below the curve the heat supplied is less than the equilibrium conductive heat flow.

For a secular decrease of temperature at the base of the lithosphere, specified by

$$
T_{m}(t)=T_{m}(0) \exp (-\lambda t)
$$

we find the long-term solution, independent of the initial condition:

$$
Q_{0}(t)=K \frac{T_{m}(t)}{L} \frac{\sqrt{\lambda \tau}}{\sin \sqrt{\lambda \tau}}=Q_{m}(t) \frac{\sqrt{\lambda \tau}}{\sin \sqrt{\lambda \tau}}
$$

where $K$ is the thermal conductivity. This transient has a similar expression than the one for a decreasing heat flux. In practice, the mantle temperature decreases by a few hundred degrees per billion years, and this represents a small fractional change. Thus, if one uses an exponential law to approximate this secular decrease, the "effective" decay constant is much smaller than in the previous calculation. The correction is therefore small.

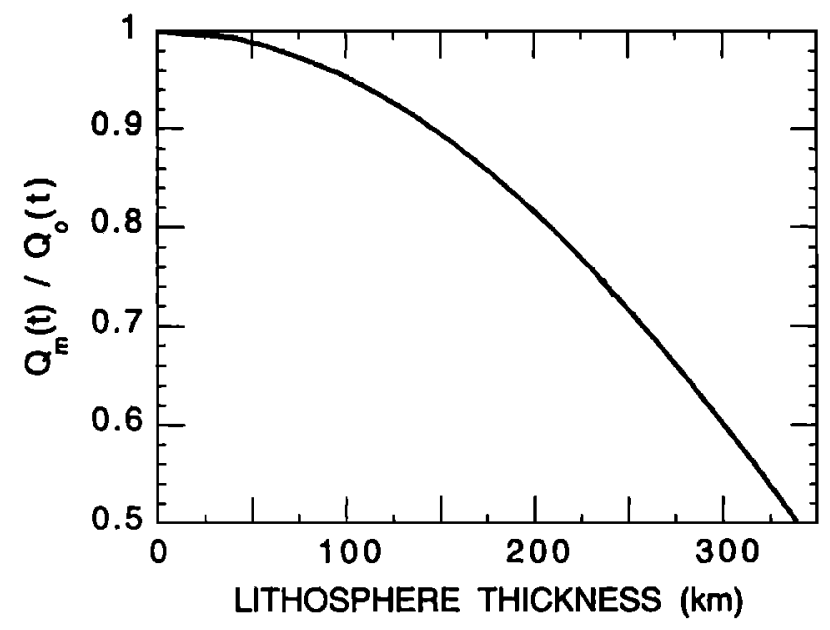

Figure 12. The ratio between heat flows at the base of the lithosphere and at the top, for a secular decrease $Q_{m} \exp (-\lambda t)$ of mantle heat flow.

\section{Appendix C: Secular Cooling and Lithospheric Thickening}

In order to model the effect of the secular decrease in mantle heat flow on the thickness of the lithosphere, the base of the lithosphere is defined by given viscosity, that is, a depth above which mantle material is too strong to deform significantly. For a temperature and pressure dependent rheology, this may be approximated by a linear function relating basal temperature to depth, $T_{m}=T_{0}+\gamma g \rho z$ where $\gamma$ is the slope of the softening curve, $\rho$ is the lithosphere density, and $g$ is the acceleration of gravity. The temperature and lithosphere thickness following a stepwise change in heat flow $\Delta Q$ at the base of the lithosphere can be determined in a linear approximation [Gliko and Mareschal, 1989]. The lithosphere thickness $L(t)$ is given by

$$
L(t)=L_{0}-\frac{\Delta Q}{K(\beta-\gamma g \rho)} 2 \sqrt{\frac{t}{\pi \tau}}+\ldots
$$

where $L_{0}$ is the initial lithosphere thickness, $K$ is the thermal conductivity, $\beta$ is the temperature gradient, and $\tau=L_{0}^{2} / \kappa$. For the secular decrease in mantle heat flow, $Q(t)=Q_{m} \exp (-\lambda t)$, the linear approximation yields for $\lambda t<1$ :

$$
L(t)=L_{0}\left(1+\frac{4 \lambda t}{3} \sqrt{\frac{t}{\pi \tau}}+\mathcal{O}\left((t / \tau)^{1 / 2}\right)\right)
$$

The lithospheric thickness in equilibrium with surface heat flow (equation (B3)) is

$$
L_{e}(t) \approx L_{0}(1+\lambda(t-\tau / 2)+. .)
$$

Retaining only the low-order terms, we obtain the difference between the lithospheric thickness and the apparent thickness determined from surface heat flow:

$$
\Delta L=L_{0}\left(\frac{4}{3} \lambda t \sqrt{\frac{t}{\pi \tau}}-\lambda(t-\tau / 2)\right)
$$

This equation above is limited to the leading terms of the series expansion and is valid only for $\lambda \tau<1$ and $\lambda t<1$. With the same values for $\lambda$ and $\tau$ as used in Appendix B, we find that for $t=10^{9}$ years, $\Delta L / L \approx$ $10 \%$.

Acknowledgments. The authors are grateful for the constant support of the Institut National des Sciences de l'Univers (Conseil National de la Recherche Scientifique, France) and the Natural Science and Engineering Research Council (Canada). This is Lithoprobe publication 889 .

\section{References}

Abbott, D., L. Burgess, J. Longhi, and W.H.F. Smith, An empirical thermal history of the Earth's upper mantle, $J$. Geophys. Res., 99, 13835-13850, 1994. 
Allègre, C.J., S.R. Hart, and J.F. Minster, Chemical structure and evolution of the mantle and continents determined by inversion of $\mathrm{Nd}$ and $\mathrm{Sr}$ isotopic data, II, Numerical experiments and discussion, Earth Planet. Sci. Lett., $66,191-213,1983$.

Allègre, C.J., E. Lewin, and B. Dupré, A coherent crustmantle model for the Uranium-Thorium-Lead isotopic system, Chem. Geol., 70, 211-234, 1988.

Anderson, D.L., Geophysics of the continental mantle: An historical perspective, in Continental Mantle, edited by M. Menzies, pp. 1-30, Clarendon, Oxford, England, 1990.

Ashwal, L.D., P. Morgan, S.A. Kelley, and J. Percival, Heat production in an Archean crustal profile and implications for heat flow and mobilization of heat producing elements. Earth Planet. Sci. Lett., 85, 439-450, 1987.

Birch, F., Heat from radioactivity, in Nuclear Geology, edited by H. Faul, pp. 148-175, John Wiley, New York, 1954.

Birch, F., E.R. Roy, and E.R. Decker, Heat flow and thermal history in New England and New York, in Studies of Appalachian Geology, edited by E. An-Zen, pp. 437-451, Wiley-Interscience, New York, 1968.

Boland, A.V., and R.M. Ellis, Velocity structure of the Kapuskasing uplift, northern Ontario, from seismic refraction studies, J. Geophys. Res., 94, 7189-7204, 1989.

Buck, W.R., and E.M. Parmentier, Convection beneath young oceanic lithosphere: Implications for thermal structure and gravity, J. Geophys. Res., 91, 1961-1974, 1986.

Cermak, V., and L. Bodri, Temperature structure of the lithosphere based on 2-D temperature modeling applied to central and eastern Europe, in Thermal Modeling in Sedimentary Basins, edited by J. Burrus, pp. 7-31, Technip, Paris, 1986.

Chapman, D.S., Thermal gradients in the continental crust, in The Nature of the Lower Continental Crust, edited by J.B. Dawson, Geol. Soc., Spec. Publ., 24, 63-70, 1986.

Clark, S.P., and A.E. Ringwood, Density distribution and constitution of the mantle, Rev. Geophys., 2, 35-88, 1964.

Clauser, C., and E. Huenges, Thermal conductivity of rocks and minerals, in Rock Physics and Phase Relations: A Handbook of Physical Constants, AGU Ref. Shelf Ser., vol. 3, , edited by T.J. Ahrens, pp. 105-129, AGU, Washington, D.C., 1995.

Clowes, R.M., F.A. Cook, A.G. Green, C.E. Keen, J.N. Ludden, J.A. Percival, G.M. Quinlan, and G.F. West, LITHOPROBE - New perspectives on crustal evolution, Can. J. Earth Sci., 29, 1831-1864, 1992.

Condie, K.C., Plate Tectonics and Crustal Evolution, 3rd ed., Pergamon, Tarrytown, N.Y., 1993.

Davaille, A., and C. Jaupart, Transient high Rayleigh number thermal convection, J. Fluid Mech., 253, 141-166, 1993a.

Davaille, A., and C. Jaupart, Thermal convection in lava lakes, Geophys. Res. Lett., 20, 1827-1830, 1993b.

Davaille, A., and C. Jaupart, Onset of thermal convection in fluids with temperature dependent viscosity: Application to the oceanic mantle, J. Geophys. Res., 99, 19853-19866, 1994.

Doin, M.P., and L. Fleitout, Thermal evolution of the oceanic lithosphere: An alternative view, Earth Planet. Scı. Lett., $142,121-136,1996$.

Doin, M.P., L. Fleitout, and D. McKenzie, Geoid anomalies and the structure of continental and oceanic lithospheres, J. Geophys. Res., 101, 16119-16136, 1996.

Doin, M.P., L. Fleitout, and U.R. Christensen, Mantle convection and stability of depleted and undepleted continental lithosphere, J. Geophys. Res., 102, 2771-2788, 1997.

Doucouré, C.M., and P. Patriat, Thermal diffusivity of the lithosphere derived from altimetry and bathymetry profiles across the southwest Indian ridge, Geophys. Res. Lett., 19, 1543-1546, 1992.
Drury, M.J., Heat flow and heat generation in the Churchill Province of the Canadian Shield and their paleotectonic significance, Tectonophysics, 115, 25-44, 1985.

Drury, M.J., and A.E. Taylor, Some new measurements of heat flow in the Superior Province of the Canadian Shield, Can. J. Earth Sci., 24, 1486-1489, 1987.

Durrheim, R.V., and W.D. Mooney, Archean and Proterozoic crustal evolution: Evidence from crustal seismology, Geology, 19, 606-609, 1991.

Eade, K.E., and W.F. Fahrig, Geochemical evolutionary trends of continental plates, A preliminary study of the Canadian Shield, Geol. Surv. Can. Bull., 179, 59 pp., 1971.

England, P.C., E.R. Oxburg, and S.W. Richardson, Heat refraction in and around granites in north-east England, Geophys. J. R. Astron. Soc., 62, 439-455, 1980.

Fleitout, L., and D.A. Yuen, Secondary convection and the growth of the oceanic lithosphere, Phys. Earth Planet. Inter., 36, 181-212, 1984.

Fountain, D.M., and M.H. Salisbury, Exposed cross-sections of the continental crust: Implications for crustal structure petrology, and evolution, Earth Planet. Sci. Lett., 56, 263277,1981 .

Fountain, D.M., M.H. Salisbury, and K.P. Furlong, Heat production and thermal conductivity of rocks from the Pikwitonei-Sachigo continental cross section, central Manitoba: Implications for the thermal structure of Archean crust, Can. J. Earth Sci., 24, 1583-1594, 1987.

Galer, S.J.G., S.L. Goldstein, and R.K. O'Nions, Limits on chemical and convective isolation in the Earth's interior, Chem. Geol., 75, 257-290, 1989.

Galson, D.A., Heat production in the Ivrea and Strona Ceneri zones, Ph.D. thesis, Univ. of Cambridge, Cambridge, England, 1983.

Gibert, D., and V. Courtillot, Thermal isostasy of the South Atlantic: A new approach, Geophys. Res. Lett., 17, 251$254,1990$.

Gliko, A., and J.-C. Mareschal, On the validity of the linear approximation to Stefan problems, Geophys. J. Int., 99, 801-809, 1989.

Green, A.G., B. Milkereit, A. Davidson, C. Spencer, D.R. Hutchinson, W.F. Cannon, M.W. Lee, W.F. Ageana, J.C. Behrendt, and W.J. Hinze, Crustal structure of the Grenville Front and Adjacent terranes, Geology, 16, 788$792,1988$.

Guillou, L., and C. Jaupart, On the effect of continents on mantle convection, J. Geophys. Res., 100, 24217-24238, 1995.

Guillou, L., J.-C. Mareschal, C. Jaupart, C. Gariépy, G. Bienfait, and R. Lapointe, Heat flow gravity and structure of the Abitibi belt, Superior Province, Canada: Implications for mantle heat flow, Earth Planet. Sci. Lett., 122, 103-123, 1994.

Guillou-Frottier, L., J.-C. Mareschal, C. Jaupart, C. Gariépy, R. Lapointe, and G. Bienfait, Heat flow variations in the Grenville Province, Canada, Earth Planet. Sci. Lett., 136, 447-460, 1995.

Guillou-Frottier, L., C. Jaupart, J.-C. Mareschal, C. Gariépy, G. Bienfait, L.Z. Cheng, and R. Lapointe, High heat flow in the Thompson Belt of the Trans-Hudson Orogen, Canadian Shield, Geophys. Res. Lett., 23, 3027-3030, 1996.

Gurnis, M., Large-scale mantle convection and the aggregation and dispersal of supercontinents, Nature, 332, 695$699,1988$.

Haack, U., On the content and vertical distribution of $\mathrm{K}$, $\mathrm{Th}$, and $\mathrm{U}$ in the continental crust, Earth Planet. Sci. Lett., 62, 360-366, 1983.

Hirth, G., and D.L. Kohlstedt, Water in the oceanic upper mantle: Implications for rheology, melt extraction and 
the evolution of the lithosphere, Earth Planet. Sci. Lett., 144, 93-108, 1996.

Hoffman, P.F., Precambrian geology and tectonic history of North America, in The Geology of North America: An Overview, edited by A.W. Bally and E.R. Palmer, pp. 447-512. Geol. Soc. of Am., Boulder, Colo., 1989.

Holbrook, W.S., W.D. Mooney, and N.I. Christensen, The seismic velocity structure of the deep continental crust, in Continental Lower Crust edited by D.M. Fountain, R. Arculus, and R.W. Kay, pp. 1-44, Elsevier Sci., New York, 1992.

Jaupart, C., Horizontal heat transfer due to radioactivity contrasts: Causes and consequences of the linear heat flow-heat production relationship, Geophys. J. R. Astron. Soc., 75, 411-435, 1983.

Jaupart, C., and B. Parsons, Convective instabilities in a variable viscosity fluid cooled from above, Phys. Earth Planet. Inter., 39, 14-32, 1985.

Jaupart, C., J.G. Sclater, and G. Simmons, Heat flow studies: Constraints on the distribution of uranium, thorium and potassium in the continental crust, Earth Planet. Sci. Lett., 52, 328-344, 1981.

Jaupart, C., J.R. Mann, and G. Simmons, A detailed study of the distribution of heat flow and radioactivity in New Hampshire (USA), Earth Planet. Sci. Lett., 59, 267-287, 1982.

Jessop, A.M., T.J. Lewis, A.S. Judge, A.E. Taylor, and M.J. Drury, Terrestrial heat flow in Canada, Tectonophysics, 103, 239-261, 1984.

Jordan, T.H., The continental tectosphere, Rev. Geophys., $13,1-12,1975$.

Jordan, T.H., Composition and development of the continental tectosphere, Nature, 274, 544-548, 1978.

Jordan, T.H., Continents as a chemical boundary layer, Trans. R. Soc. London Ser. A, 301, 359-373, 1981.

Karato, S., and P. Wu, Rheology of the upper mantle: A synthesis, Science, 260, 771-778, 1993.

Lachenbruch, A.H., Crustal temperature and heat production: Implications of the linear heat flow relation, J. Geophys. Res., 75, 3291-3300, 1970.

Lenardic, A., On the heat flow variations from archean cratons to proterozoic mobile belts, J. Geophys. Res., 102, 709-721, 1997.

Lenardic, A., and W.M. Kaula, Near surface thermal/chemica boundary layer convection at infinite Prandtl number: Two-dimensional numerical experiments, Geophys. $J$. Int., 126, 689-711, 1996.

Lister, C.R.B., Geoid anomalies over cooling lithosphere: Source for a third kernel of upper mantle parameters and thus an inversion, Geophys. J. R. Astron. Soc., 68, 219$240,1982$.

Mareschal, J.-C., C. Pinet, C. Gariépy, C. Jaupart, G. Bienfait, G. Dalla-Coletta, J. Jolivet and R. Lapointe, New heat flow density and radiogenic heat production data in the Canadian Shield and the Québec Appalachians, Can. J. Earth Sci., 26, 845-852, 1989.

Mareschal, J.-C., L. Guillou-Frottier, L. Cheng, C. Gariépy, and C. Jaupart, Heat Flow in the Trans-Hudson Orogen. LITHOPROBE Rep. 62., pp. 106-114, University of Saskatchewan, Saskatoon, Sask., 1997.

McConnell, R.K., Viscosity of the mantle from relaxation time spectra of isostatic adjustments, J. Geophys. Res., 73, 349-386, 1968.

McKenzie, D.P., Some remarks on the movement of small melt fractions in the mantle, Earth Planet. Sci. Lett., 95, 53-72, 1989.

McKenzie, D.P., and M.J. Bickle, Volume and composition of melt generated by extension of the lithosphere, J. Petrol., 29, 625-679, 1988.
Mezger, K., Temporal evolution of regional granulite terranes: Implications for the formation of the lowermost continental crust, in Continental Lower Crust, edited by D.M. Fountain, R. Arculus, and R.W. Kay, pp. 447-478, Elsevier, New York, 1992.

Montagner, J.P., Can seismology tell us anything about convection in the mantle?, Rev. Geophys., 32, 115-137, 1994.

Morgan, P., Crustal radiogenic heat production and the selective survival of continental crust, J. Geophys. Res., 90, C561-C570, 1985.

Morgan, P., and J.H. Sass, Thermal regime of the continental lithosphere, J. Geodyn., 1, 143-166, 1984.

Nakada, M., Rheological structure of the Earth's mantle from glacial rebound in Laurentide, J. Phys. Earth, 31, 349-386, 1983.

Nisbet, E.G., M.J. Cheadle, N.T. Arndt, and M.J. Bickle, Constraining the potential temperature of the Archean mantle: A review of the evidence from komatiites, Lithos, 30, 291-307, 1993.

Nyblade, A.A., and H.N. Pollack, A global analysis of heat flow from Precambrian terrains: Implications for the thermal structure of Archean and Proterozoic lithosphere, $J$. Geophys. Res., 98, 12207-12218, 1993.

Ogawa, M., G. Schubert, and A. Zehib, Numerical simulations of three dimensional thermal convection in a fluid with strongly dependent viscosity, J. Fluid Mech., 233, 299-328, 1991.

O'Nions, R.K., N.M. Evensen, and P.J. Hamilton, Geochemical modeling of mantle differentiation and crustal growth, J. Geophys. Res., 84, 6091-6101, 1979.

Parker, R.L., and D.W. Oldenburg, Thermal models of oceanic ridges, Nature Phys. Sci., 242, 137-139, 1973.

Parsons, B., and D.P. McKenzie, Mantle convection and the thermal structure of the plates, J. Geophys. Res., 83, 4485-4495, 1978.

Peltier, W.R., Ice age geodynamics, Annu. Rev. Earth Planet. Sci., 9, 199-225, 1981.

Percival, J., editor, The Kapuskasing transect of LITHOPROBE, Can. J. Earth Sci., 31, 1031-1286, 1994.

Percival, J.A., A.G. Green, B. Milkereit, F.A. Cook, W. Geiss, and G.F. West, Seismic reflection profiles across deep continental crust exposed in the Kapuskasing uplift structure, Nature, 342, 416-420, 1989.

Pinet, C., and C. Jaupart, The vertical distribution of radiogenic heat production in the Precambrian crust of Norway and Sweden: Geothermal implications, Geophys. Res. Lett., 14, 260-263, 1987.

Pinet, C., C. Jaupart, J.-C. Mareschal, C. Gariépy, G. Bienfait, and R. Lapointe, Heat flow and structure of the lithosphere in the eastern Canadian Shield, J. Geophys. Res., 96, 19941-19963, 1991.

Pollack, H.N., Cratonization and thermal evolution of the mantle, Earth Planet. Sci. Lett., 80, 175-182, 1986.

Pollack, H.N., and D.S. Chapman, On the regional variation of heat flow, geotherms, and lithospheric thickness, Tectonophysics, 38, 279-296, 1977.

Pollack, H.N., and J.H. Sass, Thermal regime of the lithosphere, in Handbook of Terrestrial Heat Flow Density Determination, edited by R. Haenel, L. Rybach, and L. Stegena, pp. 301-308, Kluwer Acad., Norwell, Mass., 1988.

Richter, F.M., H.C. Nataf, and S.F. Daly, Heat transfer and horizontally averaged temperature of convection with large viscosity variations, J. Fluid Mech., 129, 173-192, 1983.

Roy, R.F., D.D. Blackwell, and F. Birch, Heat generation of plutonic rocks and continental heat flow provinces, Earth Planet. Sci. Lett., 5, 1-12, 1968.

Roy, R.F., A.E. Beck, and Y.S. Touloukian, Thermophysical properties of rocks, in Physical Properties of Rocks 
and Minerals, vol. 2, McGraw-Hill CINDAS data series on material properties, edited by Y.S. Touloukian, W.R. Judd, and R.F. Roy, pp. 409-502, McGraw-Hill, New York, 1981.

Rudnick, R.L., Xenoliths: Samples of the lower continental crust, in Continental Lower Crust, edited by D.M. Fountain, R. Arculus, and R.W. Kay, pp. 269-316, Elsevier, New York, 1992.

Rudnick, R.L., and D.M. Fountain, Nature and composition of the continental crust: A lower crustal perspective, Rev. Geophys., 33, 267-309, 1995.

Schärmeli, G., Identification of radiative thermal conductivity in olivine up to $25 \mathrm{kbar}$ and $1500 \mathrm{~K}$, in Proceedings of 6th AIRAPT Conference, edited by K.D. Timmerhauf and M.S. Barber, pp. 60-74, Plenum, New York, 1979.

Schatz, J.F., and G. Simmons, Thermal conductivity of Earth materials, J. Geophys. Res., 77, 6966-6983, 1972.

Sclater, J.G., and J. Francheteau, The implication of terrestrial heat flow observations on current tectonic and geochemical models of the crust and upper mantle of the Earth, Geophys. J. R. Astron. Soc., 20, 509-542, 1970.

Sclater, J.G., C. Jaupart, and D. Galson, The heat flow through oceanic and continental crust and the heat loss from the Earth, Rev. Geophys., 18, 269-311, 1980.

Shaw, D.M., J.J. Cramer, M.D. Higgins, and M.G. Truscott, Composition of the Canadian Precambrian Shield and the continental crust of the Earth, in Nature of the Lower Continental Crust, edited by J.B. Dawson et al., pp. 257282, Geol. Soc. of London, 1986.

Smithson, S.B., and I.B. Ramberg, Gravity interpretation of the Egersund anorthosite complex, Norway: Its petrological and geothermal significance, Bull. Geol. Soc. Am., 90, 199-204, 1979.

Swanberg, C.A., M.D. Chessmann, G. Simmons, S.B. Smithson, G. Gronlie, and K.S. Heier, Heat flow - heat generation studies in Norway, Tectonophysics, 23, 31-48, 1974.

Taylor, S.R., and S.M. McLennan, The Continental Crust: Its Composition and Evolution. 312 pp., Blackwell, Cambridge, Mass., 1985.

Taylor, S.R., and S.M. McLennan, The geochemical evolution of the continental crust, Rev. Geophys., 33, 241-265, 1995.
Turcotte, D.L., and D.C. McAdoo, Geoid anomalies and the thickness of the lithosphere, J. Geophys. Res., 84, 28312837, 1979.

Vasseur, G., and R.N. Singh, The effects of random horizontal variations in the radiogenic heat source distribution and its relationship with heat flow, J. Geophys. Res., 91, 10397-10404, 1986.

Wasserburg, G.J., G.J.F. MacDonald, F. Hoyle, and W.A. Fowler, Relative contributions of uranium, thorium and potassium to heat production in the Earth, Science, 143, 465-467, 1964.

Wedepohl, K.H., Chemical fractionation and composition of the continental crust, Geol. Rundsch., 80, 207-223, 1991.

White, D.B., The planforms and onset of convection with a temperature dependent viscosity, J. Fluid Mech., 191, 247-286, 1988.

Wu, J., and R.F. Mereu, Crustal structure of the Kapuskasing uplift from LITHOPROBE near-vertical wide-angle seismic reflection data, J. Geophys. Res., 97, 17441-17453, 1992.

Zhong, S., and M. Gurnis, Dynamic feedback between a continent-like raft and thermal convection, J. Geophys. Res., 98, 12219-12232, 1993.

A. Davaille and C. Jaupart, Institut de Physique du Globe, 4. Place Jussieu, 75252, Paris Cedex 5, France. (email: davaille@volcan.ipgp.jussieu.fr; cj@ccr.jussieu.fr)

L. Guillou-Frottier, BRGM, DR/MGG, B.P. 6009, 3 av. C. Guillemin, 45060, Orléans Cedex 2, France. (e-mail: lguillou@u26.brgm.fr)

J.C. Mareschal (Corresponding author), GEOTOP, Université du Québec à Montréal, P.O. 8888, sta. "Downtown", Montreal, Québec, H3C3P8, Canada. (email: jcm@volcan.geotop.uqam.ca)

(Received August 1, 1997; revised February 24, 1998; accepted April 21, 1998.) 